\title{
تأثير إستخدام الرحلات المعرفية على بعض نواتج التعلم في الرقص
}

\section{المديث}

"ا.أ.د.د / وسام عادل العيد امين

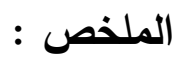

يهـدف البحث الـى التعرف على تأثير إستخدام الرحلات المعرفيـة على كـلاً مـن مستوى التحصيل المعرفي و مستوى الأداء المهارى لرقص الحديث لاى عينة البحث الأساسية و استخدمت الباحثة المنهج التجريبي لمناسبته لطبيعة هذا البحث من حيث التصميم التجريبي الذي يعتمد علي القياس القبلي والبعدي لمجموعتين إحداهما تجريبية باستخدام الرحلات المعرفية والأخرى ضـابطة باستخدام الأسلوب التقليدي على مجتمع البحث بالطريقة العمدية من طالبات الفرقة الثانية بكلية

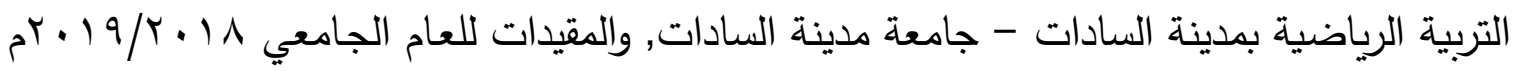

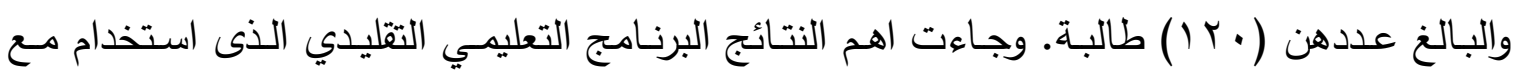
"المجموعة الضـابطة" أدى إلى تحسين في جوانب التعلم لمهارات الرقص الحديث المختارة "قيد البحث" ، حيث أظهرت فروق معنوية بين القياس القبلي والبعدي لصالح القياس البعدي وكذلك في نسبة التحسن لصـالح القياس البعدي - الرحلات المعرفية التي طبقت على "الهجموعة التجريبية" أدت إلى تحسين في جوانب التعلم لمهارات الرقص الحديث المختارة "قيد البحث" ، حيث أظهرت فروق معنويـة بين القياس القبلي والبعدي لصـالح القياس البعدي وكذلك في نسبة التحسن لصالح

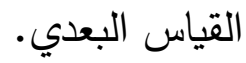

الكلمات الرئيسية الرحلات المعرفية , نواتج التعلم , الرقص الحديث

" أستاذ مساعد كلية التربية الرياضية جامعة مدينة السادات 
لقد شهد العقد الأخير من القرن الماضـي والسنوات الماضية من القرن الحالي العديد من الأفكار الجديدة والمبتكرة في مجال التربية والتعليم , وخاصـة ما يتصل منها باستثمار الإمكانات التي توفرها تكنولوجيا المعلومات والاتصالات , مثل التعلم الإلكتروني , والتعلم المتنقل , والتعلم عبر الإنترنت وغيرها من العناوين التي تبرز مدى الاهتمام التي تحظى به التقنيات الحديثة في دعم الأفكار الجديدة لتطوير أساليب التدريس •

والفوائد التربوية التي تحدث من استخدام تكنولوجيا التعليم في التدريس تجعل التعليم محسوسا كما

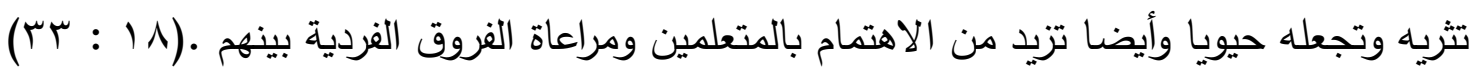
ويعتبر التطوير المستمر للتكنولوجيا وتطبيقاتها لخدمة الأهداف التربوية سيعضد من قدرتها

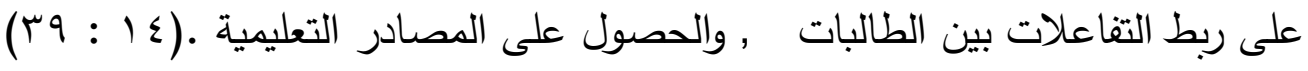

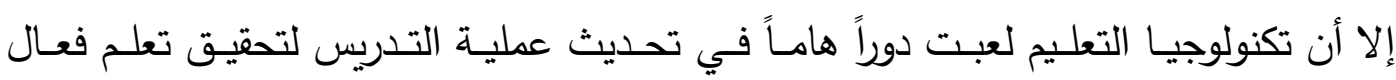
ولتحقيق أكبر قدر من النتائج التعليمية المرغوبة , حيث أن التطبيق الواعي للتكنولوجيا سوف يزيد من إنتاجية العملية التعليمية ويحرر المعلم من الأعمال الروتينية , ويضع المتعلم في مواقف تحفزهم

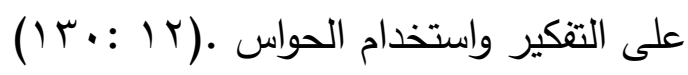
و توظيف الإنترنت في العملية التعليمية يتمثل في تقديم المنهج والتدريس للطالبات في صورة برنامج تعليمي منشور على الأنترنت أو صفحة تعليمية على الإنترنت تستخدم كمصدر الاسى في التعليم والتعلم أو كمصدر تعزيزي للتعلم الصفي ويمكن الدخول على هذه الصفحة من قبل الطالبات الصنات , ويمكن أن يحتوى البرنامج أو الصفحة الموجودة على الإنترنت على معلومات عن المقرر كمفردات الدحتوى وملخصـات الـدروس والتمرينـات والمراجـع والتعـرف بمعـد الصـفحة , إلى جانب الـربط بالمصـادر والمواقع المختلفـة على الإنترنت ذات الصـلة بطبيعـة المقرر , ومـع تطور أداء إنثــاء الصفحات على الإنترنت , أصبح بإمكان المعلم بناء مواقع وصفحات لتوجيه الطالبات من خلالها , وهذا يجعل من السهل تحديث المعلومات المتضمنة بها ويكون التدريس بواسطة الإنترنت قابل للتعديل والتطوير لمواكبة التغيير السريع في المعلومات الدراسية ـ ( ( : 97 () 
والاتجاهات التربويـة الحديثة تؤكد على ضرورة إيجاد أفضل الطرق لتوفير تعليمية تفاعلية مناسبة لجذب اهتمام المتعلمين , وحثهم على التعلم وتبادل الآراء والحوار فلا يكون متلقياً للمعلومات فقط بل مشاركاً إيجابياً وباحثاً عن المعلومة والمعرفة بكل الوسائل الممكنة ومستخدماً مجموعة من الإجـراءات العلميـة تحـت إثـراف مدرسـه وتقويمـه، وتعـد عمليـة دمــ تقنيـات المعلومـات ممثلـهـ بالحاسوب والانترنت والوسائط المتعددة بالعملية التدريسية من أنجح الوسائل لإيجاد هذه البيئات الثرية بمصادر التعلم والتعليم بما يحقق احتياجات واهتمامات المتعلمين ، وتعزيز دافعيتهم من جهة، وخدمة العملية التعليمية والارتقاء بمخرجاتها من جهة آخرى. (1 : צ ب) ومن الاستراتيجيات الحديثة التي تساعد في تحسين عملتي التعليم والتعلم , وجعل المتعلم أكثر نشاطاً وإيجابية في الحصول على المعلومة من خلال نشاطاته وتفاعله هي استراتيجية الرحلات عبر الويب , فهي واحدة من التوجهات الحديثة لتحقيق التعلم الفعال والنشط في العملية التعليمية , كما أنهـا تتسـم مـع الـدور الحديث للمعلـم بكونــه مرشـداً وموجهـاً للعمليـة التعليميـة لا نـاقلاً للمعرفـة

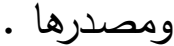

وقد اكتسبت الرحلات المعرفية عبر الويب كاستراتيجية تعليمية موجهه في التعلم من خلال شبكة الإنترنت اهتماما كبيراً من المربيين , وهى يمكن أن تكون وسيلة فعالة لتتظيم موارد الإنترنت

ومساعدة المتعلمين على اكتساب معرفة جديدة من خلال بيئة التعلم الموجهة ـ (10 : با ) وتعتبر الرحلات المعرفية نمطاً تربوياً بنائياً حيث تتمحور حول المتعلم الرحال والمستكثف, وتسـاعد على تحقيق أهداف تعليمية محددة مسبقاً ومخططاً لها بعناية , كما تقوم بتشجيع العمل التعاوني , وتبادل الآراء والأفكار بين الطالبات وذلك لا يمنع العمل الفردى. (ד ( : ع ب) والرحلات المعرفية عبر الويب تتفق كإستراتيجية تعليمية مع الأسس والمبادئ التي يقوم عليها المـدخل البنـائي في التصـميم التعليمي , فمـن خصـائص هذا المــخل أنـه يتمركز حـول المـعلم , ويؤكد على بنـاء المتعلم للمعرفـة بنفسه ورفض التلقي السلبى لها والتأكيد على المشـاركة النشطة للمتعلم في عملية التعلم وربط معارفه الجديدة بخبراته ومعارفه السابقة , والتأكيد على العمل الجماعي مـع الاعتراف بذاتيـة المتعلم , وجعله واعياً بدوره ومسئوليته الفرديـة , وأن تكون مهام التعلم واقعيـة وذات معنى , وبذلك تعد إستراتيجية الرحلات المعرفية إحدى استراتيجيات التعلم التي تتوافر فيها 
أسس الفكر البنائي ومبادئـه مـن حيث أنها تستهدف تدريب المـعلم وتثـيعه على بنـاء المعرفـة وإنتاجها بنفسه بدلاً من نقلها إليه , كما أن تتفيذ الطالبات لخطوات الاستراتيجية يمكنه من اكتشاف معارف واكتساب خبرات جديدة , فتتظظم هذه الخبرات في الإطار الموجود لديه بالفعل , لتؤدي إلى إبداع تراكيب معرفيـة جديدة تسـاعده على إعطاء معنى لخبراتـه التي مر بها , وكلمـا مر المتعلم بخبرات جديدة حدث تعديل للمنظومة المعرفية الموجودة لديه.(V V : . I ) مثنكلة البحث:

يعد ظهور عصر العولمة ومجتمع المعلوماتية الاككترونية بشكل متسارع ، وكذلك التطور الهائل في شبكة المعلومات الدولية وزيادة الخدمات التي تقدمها جعلت النظم التعليمية في مواجهة الكثير من التحديات الضخمة التي تستلزم التصدي لها بفكر تربوي جديد واستراتيجيات متطورة، حتى تمتلك الاجيـال القادمـة مهارات التعامـل مـع تلك التغيرات التكنولوجيـة ـ ولذا يجب التصـدي لهذه المشكلة من خـلال استخدام استراتيجيات تدريسيه التي تؤكد على المشـاركة الايجابية للمتعلم في الموقف التعليمي وتمكنه من ممارسة عمليات التقصي والاكتثاف والبحث عن المعلومات مما يجعل البيئة التعليمية تتسم بالإثارة والمتعة أثناء عملية التعلم ومن هذه الاستراتيجيات ؛ استراتيجية الرحلات المعرفية عبر الويب والتي تساعد المتعلم على التوصل إلى المعارف والمعلومات من خلال الابحار عبر شبكة المعلومات العالمية و بالنظر إلى قدرات الطالبات ندرة هذا الجيل في استخدام التقنيات الحديثة وسـهولة استخدامهم لها ممـا سيسـهل لهم فهم إجراء عمليـة البحث , وبـالنظر إلى حجم المعلومـات المتزايد على شبكة الإنترنت , فإنـا ليس مـن السـهل عليهم إجراء عملية البحث دون التشعب في موضوعات بعيدة كل البعد عن محور الاهتمام والبحث , مما يؤدى إلى تشتت جهد الطالبات في البحث عن المعلومـة المطلوبـة , وانطلاقا من ذلك جاءت الحاجـة إلى تطوير نماذج تعليمية محددة وأساليب موجها مثل الرحلات المعرفية Web Quests وتحولهم الى جيل مميز في إستخدام التكنولوجيا وتجد الباحثة ان تظهر الرقص الحديث من خـلال الفيديوهات والرسومات وبذلك فإنها تجذبهج للإبحار والاستمتاع والتشوق للمشاهدة والتطبيق بعد ذلك مما يؤدى الى الوصول الى معرفة

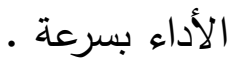


والرحلات المعرفية عبر الويب تعكس الفكر التكنولوجي الحديث في التدري المعاصر الذى يعتمد على أحدث تقنيات العصر كمصدر للمعرفة في مختلف المراحل الدراسية وكذلك المجالات المتعـدة النظريـة منهـا والتطبيقيـة , وأن المعلومـات المتـوفرة فيهـا تتسـم بالحداثـة والجديـة وفـى التخصصات المختلفة وذلك بالإضافة إلى أنها من الوسائل المستحدثة والهامـة في إكساب الناشئات العديد من العديد من المهارات والمعارف اللازمة لهم من خلال الإبحار في الثبكة الدولية للمعلومات وتعليم البحث الذاتي والتعلم التفاعلي الغير مقيد بالزمان والمكان ولمواجهة عيوب واستخدام الطريقة التقليدية المتبعة (الشرح - أداء النموذج) في التدريس •

$$
\text { هدف البحث: }
$$

التعرف على تأثير إستخدام الرحلات المعرفية عبر الويب على بعض نواتج التعلم في

$$
\text { الرقص الحديث }
$$

ا. توجد فروق ذات دلالة إحصائية بين القياسين القبلي والبعدي للمجموعة التجريبية لصـالح القياس

$$
\text { البعدي في التحصيل المعرفي قيد البحث . }
$$

r. توجد فروق ذات دلالة إحصائية بين القياسين القبلي والبعدي للمجموعة التجريبية لصـالح القياس

$$
\text { البعدي في المستوى المهارى للرقص الحديث قيد البحث . }
$$

r. توجد نسب تحسن بين القياسين القبلي والبعدي للمجموعة التجريبية لصالح القياس البعدي في التحصيل المعرفي ومستوى أداء الرقص الحديث قيد البحث .

$$
\begin{aligned}
& \text { مصطلحات البحث: } \\
& \text { • الرحلات المعرفية : }
\end{aligned}
$$

هي "بيئة تعلم موجها تقوم على الاستقصاء يتفاعل فيها المتعلمون مـع مصـادر التعلم المتاحة على شبكة الانترنت لتنمية مهارات التفكير العليا من خلال العمل التعاوني في مجموعات صغيرة".(Y ( : ( 


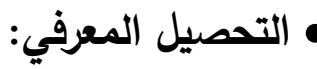

هي المجموعة الأولية من السمات التي توصل المعرفة وتصفها والتي تأخذ بشكل المهارات المتعـدة الأبعـاد المعتمـدة على التفكيـر مـن أجـل اسـتظهار واسـترجاع ومعالجـة مـدرجات الفـرد

للمعلومات.(19 (19 : (19)

\section{الرقص الحديث.}

"هو فن خلاق ومبدع يعبر عن فكرة معينة باستخدام حركات الجسم المختلفة والمتتوعة والتي

$$
\begin{aligned}
& \text { يقوم بها الفرد وفقاً لإمكانياته الذاتية". (ع:0ـ () } \\
& \text { إجـراءات البحث } \\
& \text { أولاً: منهج البحث. }
\end{aligned}
$$

استخدمت الباحثة المنهج التجريبي لمناسبته لطبيعة هذا البحث من حيث التصميم التجريبي الذي يعتمد علي القياس القبلي والبعدي لمجموعتين إحداهما تجريبية باستخدام الرحلات المعرفية والأخرى ضابطة باستخدام الأسلوب التقليدي .

\section{ثانياً: مجتمع البحث.}

تم اختيار مجتمع البحث بالطريقة العمدية من طالبات الفرقة الثانية بكلية التربية الرياضية

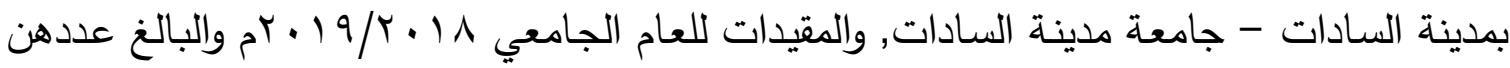

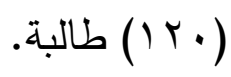

ثالثاً: عينه البحث.

تم اختيار عينة البحث بالطريقة العمدية من طالبات الفرقة الثانية بنات بكلية التربية الرياضية بمدينة السادات - جامعة مدينة السادات وقد بلغ حجم العينة قبل تطبيق البرنامج التعليمي ( . ( ) طالبة بنسبة r^٪ من المجتمع الأصلي للعينة، ثم قسمت بالطريقة العشوائية على النحو التالي : أ - المجموعة الأولى (الضابطة): وعددها ( •0) طالبة التي خضعت لأسلوب الشرح اللفظي وأداء النموذج العملي والأسلوب التقليدي في التعلم. 
ب - المجموعة الثانية (التجريبية): وعددها ( •0) طالبة التي استخدمت أسلوب الرحلات المعرفيـة ـ ويوضـح جـول( (1) أعـداد أفراد عينـة البحث للدراسـة الأساسـية وأفـراد عينـة الدراســة الاستطلاعية.

جدول(1)

توصيف مجتمع وعينه البحث ن=، ب ا

\begin{tabular}{|c|c|c|c|}
\hline النسبة المئوية & العدد & المجموعة & م \\
\hline$\% \leqslant 1.7$ & o. & الضابطة & 1 \\
\hline$\% \leqslant 1.7$ & 0. & التجريبية & $r$ \\
\hline$\% 17.7$ & $r$ r. & الاراسات الاستطلاعية & $r$ \\
\hline$\% 1 \ldots$ & ir. & الإجمالي & 0 \\
\hline
\end{tabular}

: تجانس عينة البحث .

قامت الباحثة بإيجاد التجانس لعينه البحث (الأساسية، الاستطلاعية) والبالغ عددهن (. Y ) طالبة للتأكد من وقوعها تحت المنحنى الاعتدالي وذلك في المتغيرات التالية وذلك كما يوضـحه

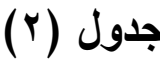

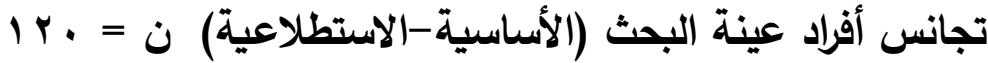

\begin{tabular}{|c|c|c|c|c|c|c|}
\hline معامل & الانحراف & الوسبط & الحتوسط & وحدة القياس & الاختبارات & م \\
\hline r.1. 1 & $7 . \vee 9$ & $17 \varepsilon$ & IT.Ar & السنتيمتر & الطول & .1 \\
\hline .rvq & V.Y & 71 & $71 . V \mathrm{~V}$ & الكيلو & الوزن &.$r$ \\
\hline $1.111-$ & $\cdot . \leqslant \varepsilon$ & Y & $r \cdot . V \leq$ & السنة & السن &.$r$ \\
\hline$. . \wedge r-$ & V.Ar & $\wedge \wedge$ & 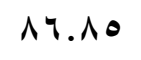 & الدرجة & الأكاء &.$\varepsilon$ \\
\hline$\cdot . \leqslant \leqslant \wedge$ & צ ז.r & 19 & 11.90 & الارجة & المعرفي & .0 \\
\hline
\end{tabular}


يتضح من جدول (r) أن معامل الالتواء لمتغيرات " الطول - الوزن - السن - معامل الذكاء - الاختبار المعرفي " لأفراد عينة البحث قد انحصرت ما بين (ب r) مما يدل على تجانس أفراد عينة البحث في هذه المتغيرات.

جذول (r)

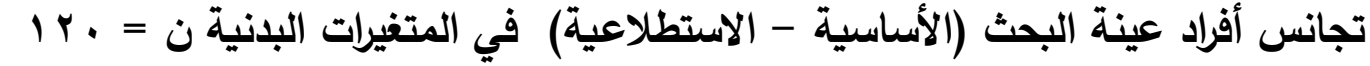

\begin{tabular}{|c|c|c|c|c|c|c|}
\hline الالتواء & المعراف المعياري & الوسيط & المستوسط & والقياس & الاختبارات & \\
\hline..$\varepsilon \cdot v$ & $r \ldots \varepsilon$ & 7. & Tr.TI & الكيلومتر & $\begin{array}{c}\text { إختبار قوة عضلات الرجلين (بالاينا } \\
\text { ملميتر) }\end{array}$ & .1 \\
\hline$\ldots$ lv & \&.V & 17 & $17.0_{0}$ & السنتميتر & إختبار الوثب العمودي من الثبات &.$r$ \\
\hline$. .1 \leqslant 9$ & Tr.AT & 71 & IV & 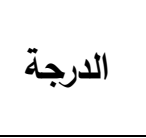 & "المرات "الانبطاح المائل من الوقوف عدى من &.$r$ \\
\hline .r.q & 1.ro & 1 r.01 & Ir.VA & الثانية & إختبار الجري المكوكى (ع ×9) أو & $\varepsilon$ \\
\hline $\begin{array}{l}- \\
. . \leqslant V T\end{array}$ & r.Ao & $1 \varepsilon$ & $\mid r . \wedge \Lambda$ & السنتميتر & إختبار ثنى الجذع من الوقوف & .0 \\
\hline $1 . r \leqslant v$ & r.90 & $r . .9$ & $\varepsilon .19$ & الثانية & إختبار الوقوف على مشط القدم & .7 \\
\hline
\end{tabular}

يتضـح مـن جدول (r) أن معامل الالتواء لاختبارات المتغيرات البدنية المختارة لأفراد عينة

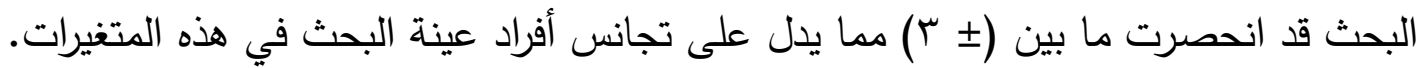
جدول (๕)

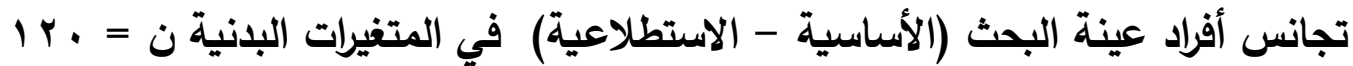

\begin{tabular}{|c|c|c|c|c|c|c|}
\hline الالتواء & المعياري & الوسيط & المستوسط & القياس & الاختبارات & \\
\hline..$\varepsilon \cdot V$ & $r \ldots \varepsilon$ & 7. & Tr.TI & الكيلومتر & إختبار قوة عضلات الرجلين (بالدينا & .1 \\
\hline
\end{tabular}




\section{مجلة نظريات ونطبيقات التربية البدنية وعلوم الرياضة}

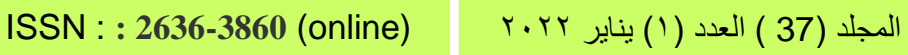

\begin{tabular}{|c|c|c|c|c|c|c|}
\hline$\ldots 1 \mathrm{lV}$ & $\varepsilon . V$ & 17 & 17.40 & السنتميتر & إختبار الوثب العمودي من الثبات &.$r$ \\
\hline$-1 \leq 9$ & Y.A. & 71 & $7 V$ & الدرجة & "إختبار بجوربي إلى أقصى عدد من & . \\
\hline.$r \cdot q$ & 1.50 & $\mid Y .01$ & I Y.VA & الثانية & إختبار الجري المكوكى (ع × &.$\varepsilon$ \\
\hline $\begin{array}{c}- \\
. . \varepsilon \vee \mu\end{array}$ & Y.A० & $1 \varepsilon$ & $\mid \mathrm{H} . \wedge \wedge$ & السنتميتر & إختبار ثنى الجذع من الوقوف & .0 \\
\hline $1 . r \varepsilon V$ & Y.9० & r. 9 & $\varepsilon \cdot 19$ & الثانية & إختبار الوقوف على مشط القدم & .7 \\
\hline
\end{tabular}

يتضـح من جدول (ع) أن معامل الالتواء لاختبـارات المتغيرات البدنيـة المختارة لأفراد عينة

البحث قد انحصرت ما بين (ب ب) مما يدل على تجانس أفراد عينة البحث في هذه المتغيرات.

(0) جدول

تجانس أفراد عينة البحث (الأسساسية- الاستطلاعية) في المتغيرات

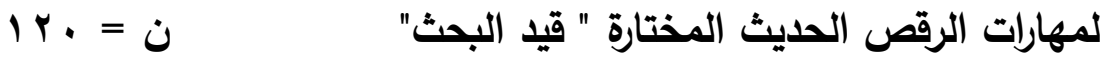

\begin{tabular}{|c|c|c|c|c|c|c|}
\hline معامل & الاندراف & الوسيط & المسابي & القياس & الاختبارات & \\
\hline$\cdot 9 \leq r$ & $.7 r$ & $r$ & $r . .9$ & الارجة & المشي & .1 \\
\hline $1 .+r q$ &. $.7 \mathrm{~V}$ & $\mu$ & r.r. & الارجة & 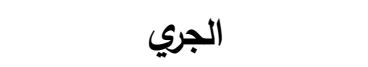 &.$r$ \\
\hline .974 & .07 & $r$ & r.Y. & الارجة & الحجل &.$r$ \\
\hline$\ldots \varepsilon 1$ & $.7 r$ & $r$ & r.r. & الارجة & الارتداء &.$\varepsilon$ \\
\hline.$v \varepsilon \wedge$ & .79 & $r$ & $r . r V$ & الارجة & النجمة & .0 \\
\hline $1 . \varepsilon \varepsilon$ & .71 & $r$ & $r . \cdot v$ & الارجة & 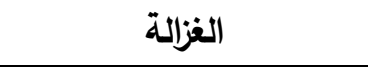 & .7 \\
\hline $.0 \leq 4$ &. .71 & $r$ & r.rt & الارجة & 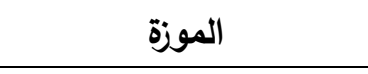 & $\cdot v$ \\
\hline $.9 r \wedge$ & .7 & $r$ & $r . r$ & الدارجة & الفجوة &.$\wedge$ \\
\hline .71 & .09 & $r$ & T.Y & الارجة & وثبة الحصان & .9 \\
\hline .000 & $.0 \varepsilon$ & $r$ & r.rA & الارجة & الزحلقة & 1. \\
\hline .197 & $.7 r$ & r.o. & r.or & الارجة & حركات التكور والمد & 11 \\
\hline $.09 \mathrm{~V}$ &. .01 & $r$ & $r .11$ & الدارجة & حركات التوزان من الثبات & $1 r$ \\
\hline $1 . .9$ &. .01 & $r$ & $r .11$ & الارجة & حركات التوزان من الحركة & 14 \\
\hline
\end{tabular}


يتضـح مـن جدول (0) أن معامـل الالتـواء لاختبـارات المتغيـرات لمهـارات الـرقص الحـديث المختارة لأفراد عينة البحث قد انحصرت ما بين (ب r) مما يدل على تجانس أفراد عينة البحث في هذه المتغيرات.

\section{ب. تكافؤ مجموعتي البحث:}

لتحقيق التكافؤ بين مجموعتي البحث التجرببية والضابطة، قامت الباحثة بإيجاد دلالة الفروق

بين المجموعتين في القياس القبلي في بعض المتغيرات المختارة. وذلك ما يوضحه جدول (†)

جدول(7)

دلالة الفروق بين مجموعتي البحث التجريبية والضابطة

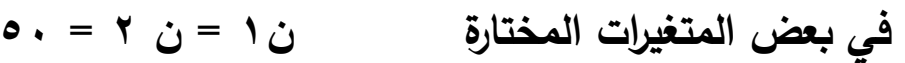

\begin{tabular}{|c|c|c|c|c|c|c|c|}
\hline \multirow{2}{*}{ " قيمة } & \multirow{2}{*}{ الفرق بين } & \multicolumn{2}{|c|}{ المجموعة الضابطة } & \multicolumn{2}{|c|}{ المجموعة التجربيية } & \multirow{2}{*}{ وحدة القياس } & \multirow{2}{*}{ المتغيرات } \\
\hline & & $\varepsilon \pm$ & س- - س & $\varepsilon^{ \pm}$ & 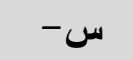 & & \\
\hline .0099 & .91 & $\varepsilon .7$. & $17 r .74$ & $Y . £ V$ & $17 \leqslant .0 \leqslant$ & السنتيمتر & الطول \\
\hline .rM &. $.1 r$ & 9.YI & 91.97 & $0.7 \leq$ & Tr.va & الكيلو جرام & 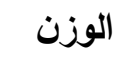 \\
\hline.$M T V$ & $\cdots \varepsilon$ & .. $\leqslant 1$ & $r \cdot . v q$ & $\cdot . \varepsilon \varepsilon$ & $r \cdot v_{0}$ & السنة & 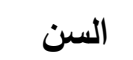 \\
\hline.$\vee \vee 4$. & I.rv & T. Y & 19 & V.ro & $\Lambda V . T r$ & الارجة & 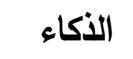 \\
\hline.$r 01$ & & r.vo & $11 . \vee 9$ & r.१. & $19.1 \%$ & الدرجة & المعرفي \\
\hline
\end{tabular}

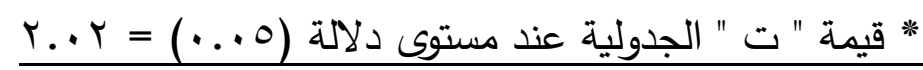

يتضـح من جدول (7) عدم وجود فروق دالة إحصـائياً عندي مستوى دلالـة (0 . . ) بين المجموعتين التجريبية والضـابطة لمتغيرات "الطول - الوزن - السن - معامل الذكاء - الاختبار المعرفي" لأفراد عينة البحث ، مما يدل على تكافؤ المجموعتين في تلك المتغيرات.

$$
\text { جدول (v) }
$$

دلالة الفروق بين مجموعتي البحث التجريبية والضابطة

\begin{tabular}{|c|c|c|c|c|c|c|c|}
\hline \multirow{2}{*}{ " ق ت " } & \multirow{2}{*}{ الفرق } & \multicolumn{2}{|c|}{ المجموعة الضابطة } & \multicolumn{2}{|c|}{ المجموعة التجريبية } & \multirow{2}{*}{ وحدة القياس } & \multirow{2}{*}{ الاختبارات البدنية } \\
\hline & & $\varepsilon^{ \pm}$ & س- س & $\varepsilon^{ \pm}$ & س- س & & \\
\hline
\end{tabular}

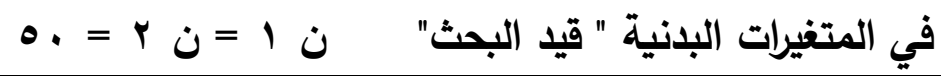




\begin{tabular}{|c|c|c|c|c|c|c|c|}
\hline & طين & & & & & & \\
\hline . & - & $18.9 \leq$ & TY.VI & $17 . .1$ & Tr..A & 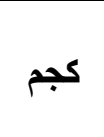 & إختبار قوة عضلات الرجلين (بالدينا \\
\hline $.90 \leq$ &.$\wedge \varepsilon$ & צ.Y & $17.1 \mathrm{~V}$ & $\varepsilon .19$ & 10.r & 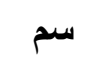 & إختبار الوثب العمودي من الثبات \\
\hline$\because \vee \wedge$ &. $.0 \wedge$ & YO.M & Tr. & $r \leq .9 \leq$ & $7 \varepsilon$ & 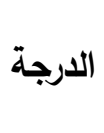 & المرات "الانبطار بيوبح إلى أقصى عدد من المن \\
\hline. .00 &.$r q$ & Y.\&Y & IT.ro & 1.10 & Ir.os & الثانية & إختبار الجري المكوكى ( ع ه9) أو \\
\hline .rVO &..$r 1$ & Y.T & 14.94 & r.01 & $1 \leq .1 \%$ & 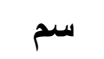 & إختبار ثنى الجذع من الوقوف \\
\hline $.1 \mathrm{VV}$ & $1 \ldots$ & $1 . V V$ & r.l. & r... & r.l. & الثانية & إختبار الوقوف على مشط القدم \\
\hline
\end{tabular}

يتضـح من جدول (V) عدم وجود فروق دالة إحصـائياً عندي مستوى دلالة (ه . •) بين المجموعتين التجريبية والضـابطة في المتغيرات البدنية المختارة "قيد البحث" ، مما يدل على تكافؤ المجموعتين في تلك المتغيرات.

$$
\text { جدول (^) }
$$

دلالة الفروق بين مجموعتي البحث التجريبية والضابطة في المتغيرات لمهارات الرقص الحديث "قيد البحث" ن $1=$

\begin{tabular}{|c|c|c|c|c|c|c|c|c|}
\hline \multirow{2}{*}{ " قيمة " } & \multirow{2}{*}{$\begin{array}{c}\text { الفرق بين } \\
\text { المتوسطين }\end{array}$} & \multicolumn{2}{|c|}{ المجموعة الضابطة } & \multicolumn{2}{|c|}{ التجمريبة } & \multirow{2}{*}{ القياس } & \multirow[t]{2}{*}{ المهارات } & \multirow[t]{2}{*}{ t } \\
\hline & & $\varepsilon \pm$ & س- & $\varepsilon \pm$ & س- & & & \\
\hline 7. & $\ldots 7$ &.$v r$ & $r .19$ & .07 & $r .1 r$ & الارجة & المشي & .1 \\
\hline 1.100 &.$r 1$ &. $.7 \mathrm{~V}$ & $r .1 \mathrm{~V}$ &. .14 & r.rA & الارجة & الجري &.$r$ \\
\hline 1.797 &. .17 & $\cdots \leqslant r$ & $r .1 r$ & $\cdot . \leqslant 7$ & r.rq & الارجة & الحجل &.$r$ \\
\hline $.90 r$ &. .19 & .00 & $r .19$ &.$v r$ & r.rA & الارجة & الارتداء &.$\varepsilon$ \\
\hline $.9 \leq 1$ &. .99 &..$\leqslant r$ & r.l. & $\cdot . \leqslant 4$ & r.19 & الارجة & النجمة & .0 \\
\hline$\cdot . \varepsilon \cdot 1$ & $\cdot . \wedge$ &. .71 & $r . .4$ & $\cdot . \wedge$ & r.10 & الدرجة & الغزالة & .7 \\
\hline $1.1 \leqslant 1$ &. .9 &.$v 1$ & r.rT &. .79 & r.rq & الارجة & الموزة &.$V$ \\
\hline
\end{tabular}




\begin{tabular}{|c|c|c|c|c|c|c|c|c|}
\hline . . $\leqslant \leqslant$. & $\ldots \varepsilon$ & . $\{\leqslant$ & r.ro & $\ldots \varepsilon \varepsilon$ & $r . r_{1}$ & الارجة & الفجوة &.$\wedge$ \\
\hline $.7 r \varepsilon$ & $\ldots 1$ &..$\leqslant 1$ & $r .19$ &..$\leqslant 9$ & r.rV & الارجة & وثبة الحصان & .9 \\
\hline 1.109 & $. .1 \leq$ &. .54 & r..ru & $.7 r$ & ק.r. & الارجة & الزحلقة & 1. \\
\hline $1 \ldots$ &. $.1 r$ &..$\leqslant r$ & r.ro & $.0 r$ & r.rA & الارجة & حركات التكور والمد & 11 \\
\hline $.0 \cdot 1$ & $\cdots 1$ & $.0 \leqslant$ & $r .1 \mu$ & $.9 r$ & $r . r 1$ & الارجة & حركات التوزان من & $.1 Y$ \\
\hline $1 . . v 1$ & .10 & .07 & r... &. $.7 \mathrm{~V}$ & r.r. & الارجة & حركات التوزان من & .14 \\
\hline
\end{tabular}

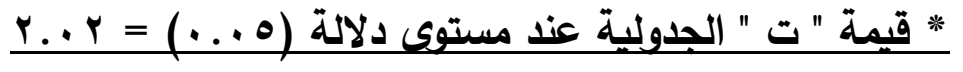

يتضـح من جدول (^) عدم وجـود فروق دالـة إحصـائياً عندي مستوى دلالـة (0. . •) بين

المجموعتين التجريبية والضابطة في المتغيرات لمهارات الرقص الحديث المختارة "قيد البحث" ، مما يدل على تكافؤ المجموعتين في تلك المتغيرات. رابعاً: وسائل وأدوات جمع البيانات. ا ـ استمارات تسجيل البيانات:

قامت الباحثة بتصميم استمارات تسجيل القياسات الخاصـة بالبحث، حيث يتوافر بها البساطة وسهولة ودقة وسرعة التسجيل من أجل تجميع البيانات وجدولتها لمعالجتها إحصائياً وهى: • استمارة تسجيل قياسات الطالبات (السن - الطول - الوزن). • استمارة تسجيل قياسات الطالبات في المتغيرات (البدنية). • استمارة تسجيل قياسات الطالبات في المتغيرات (المهارية). • استمارة تسجيل قياسات الطالبات في اختبارات (الذكاء والتحصيل المعرفي). • استمارة تسجيل قياسات الطالبات في الآراء والانطباعات. ץ ـ أجهزة للالالة على معدلات النمو وتمثلت في القياسات التالية: • العمر الزمنى: بالرجوع إلى تاريخ الميلاد(لأقرب سنة). • الطول: بواسطة إستخدام جهاز الرستاميتر (لأقرب سنتيمتر). • الوزن: بواسطة الميزان الطبي(لأقرب كيلو جرام). 


$$
\begin{aligned}
& \text { r. الأدوات المستخدمة في البحث: } \\
& \text { • ميزان طيي. } \\
& \text { • - جهاز رستامتير • }
\end{aligned}
$$

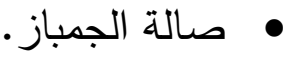

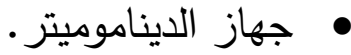

$$
\begin{aligned}
& \text { • مسطرة مدرجة لقياس المرونه"بالسنتيمتر ". } \\
& \text { • شريط قياس للمسافة "بالأمتار". } \\
& \text { • ساعه إيقاف. } \\
& \text { • • - مأقماع. } \\
& \text { • - ماشة عرض. }
\end{aligned}
$$

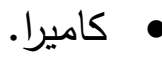

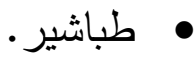

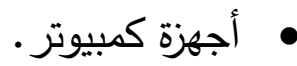

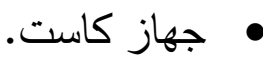

$$
\begin{aligned}
& \text { ـ ـ استمارة استطلاع آراء الخبراء (الاستبيان): }
\end{aligned}
$$

قامت الباحثة بتصميم استمارات استطلاع آراء السادة الخبراء في مجالات التعبير الحركي

والاختبارات والمقاييس والمناهج وطرق التدري. وذلك لتحديد:

مكونات عناصر اللياقة البدنية الخاصة بالرقص الابتكاري الحديث

الاختبارات التي تقيس مكونات عناصر اللياقة البننية الخاصة بالرقص الحديث.

$$
\text { • • أحديد مدى صدق عبارات الاختبار المعرفي. }
$$

• تحديد الصفات البدنية الخاصة بالرقص الابتكاري الحديث: 
حددت الباحثة المتغيرات البدنية قيد البحث من خلال الرجوع إلى الدراسات والمراجع العلمية ثم قامت بوضعها في استمارة. وتم عرضها على (0) خبراء في مجال التعبير الحركي مرفق (Y) وذلك لتحديد أهم هذه المكونات. وجدول (9) يوضح أهم عناصر اللياقة البدنية الخاصة بالرقص الابتكاري الحديث والنسبة المئوية لكل منها.
(9) جدول

نسبة اتفاق آراء الخبراء حول أهم الصفات البدنية الخاصة بالرقص الابتكاري الحديث

\begin{tabular}{|c|c|c|c|c|}
\hline النسبة المئويـة & 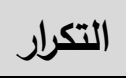 & عناصر اللياقة البدنية & & 5 \\
\hline$\% 1 \ldots$ & 0 & - التحمل العضلي & \multirow{3}{*}{ 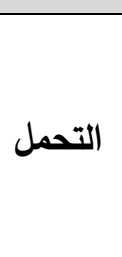 } & \multirow{3}{*}{1} \\
\hline$\% \varepsilon$ & r & - التحمل الدوري التنفسي & & \\
\hline$\%$ & 1 & تحمل السرعة & & \\
\hline$\% 1$. & $\bullet$ & التــوازن الثابت & \multirow{2}{*}{ 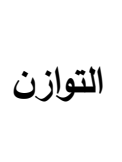 } & \multirow{2}{*}{$r$} \\
\hline$\% 1 \ldots$ & $\bullet$ & التوازن الديناميكي & & \\
\hline$\% 1 \ldots$ & 0 & - القوة العضلية الثابتة & \multirow{3}{*}{ القوة } & \multirow{3}{*}{$r$} \\
\hline$\% \varepsilon$. & r & - القوة العضلية الدينامية & & \\
\hline$\% 1$. & $\bullet$ & - القوة المميزة بالسرعة & & \\
\hline$\% 1 \ldots$ & $\bullet$ & 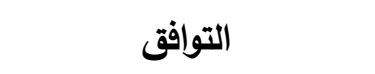 & & $\varepsilon$ \\
\hline$\% 1 \ldots$ & $\bullet$ & 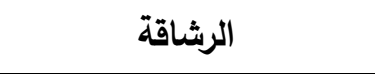 & & $\bullet$ \\
\hline$\% 1$. & $\bullet$ & 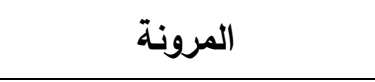 & & 9 \\
\hline$\% r$. & 1 & 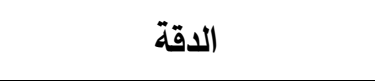 & & $v$ \\
\hline$\% \varepsilon$. & r & سرعة الاستجابة الحركية & & $\wedge$ \\
\hline
\end{tabular}

يتضـح مـن جدول(9) أن النسبة المئويـة لتحديـد مكونـات عناصـر اللياقـة البدنيـة

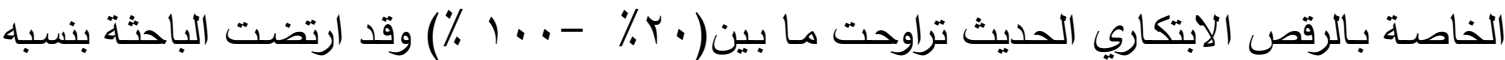

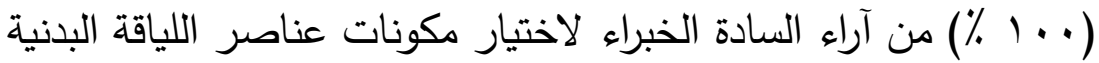
المعاملات العلمية لاختبارات عناصر اللياقة البدنية: أولاً: الصدق: - n 


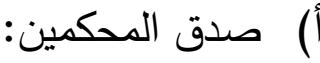 \\ : ب) (بدق التمايز}

تم حسـاب مُعامـل صدق اختبارات عناصـر اللياقـة البدنيـة قيد البحث باستخدام صـدق

التمايز عن طريق إيجاد معنويـة الفروق بين (الربيع الأعلى، الربيع الأدنى) ، وذلك بعد أن قامت

الباحثة بترتيب درجات عينة البحث الاستطلاعية والبالغ عددهن (· ·) طالبة ترتيباً تنازلياً ، ثم قامت

بإيجـاد دلالـة الفروق بين متوسطي الربـاعيين ، والجدول التالي يوضـح مُعامـل الصـدق لاختبارات

عناصر اللياقة البدنية المختارة "قيد البحث".

\section{جدول (·)}

دلاله الفروق بين الربيع الأعلى والأدنى في اختبارات

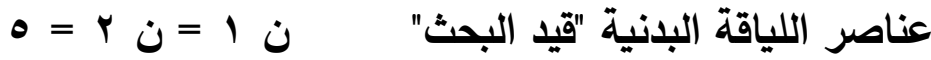

\begin{tabular}{|c|c|c|c|c|c|c|c|}
\hline \multirow{2}{*}{ " قيمة " " " } & \multirow{2}{*}{ الفرق بين } & \multicolumn{2}{|c|}{ الربيع الأدنى } & \multicolumn{2}{|c|}{ الربيع الأعلى } & \multirow{2}{*}{ وحدة } & \multirow{2}{*}{ المتغيرات } \\
\hline & & $\varepsilon \pm$ & س- & $\varepsilon^{ \pm}$ & س- & & \\
\hline$* \vee .70$ & $7 \wedge . \vee 0$ & $v . \cdot v$ & $r . .$. & Yr.O. & $q \wedge . \vee 0$ & الكيلو & الرجتبار قوة عضلات (بالدينا ملميتر) \\
\hline$* \diamond 9 \ldots$ & $1 \leqslant . \vee 0$ & .99 & $1 . .10$ & $1 \ldots$ & ro.0. & السنتيمتر & إختبار الوثب العدودي \\
\hline$* \mid r .0 q$ & $\varepsilon r \ldots$ & $\wedge . \wedge \vee$ & $01 \ldots$ & Y.r. & $9 \leq \ldots$ & الارجة & 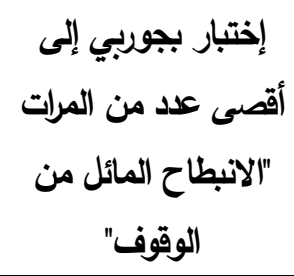 \\
\hline$* 9.71$ & T.Yo &..$\varepsilon r$ & 11.1. & $1 . . r$ & $10 . .0$ & الثانية & (إختبار الجري المكوكي \\
\hline$* 17.87$ & $0 . \leqslant \wedge$ & .90 & 11.10 & $1 . \leqslant 9$ & 17.74 & السنتيمتر & إختبار ثنى الجذع من \\
\hline$* 17 . .1$ & $v .09$ & $.7 V$ & r.s. & $1 . r 0$ & $1 . .99$ & الثانية & إختبار الوقوف على \\
\hline
\end{tabular}

* قيمة " ت " الجدولية عند مستوى دلالة (0. . •) = 
يتضـح من جدول (• (1) أن قيمـة "ت" المحسوبة أكبر من قيمـة "ت" الجدولية عند مسـتىى معنويـة (0 . • ) بين متوسطي (الربيع الأعلى ، الربيع الأدنى) ولصسالح متوسط الربيع الأعلى في اختبارات عناصر اللياقة البدنية قيد البحث ، مما يدل على صدق هذه الاختبارات. ثانياً: الثبات:

تم حسـاب معامل ثبات الاختبار بطريقهـ تطبيق الاختبار وإعـادة تطبيقهـ"

علي العينة الاستطلاعية والتي بلغت عددهن ( • ( ) طالبه من طالبات الفرقة الثانية من نفس مجتمع

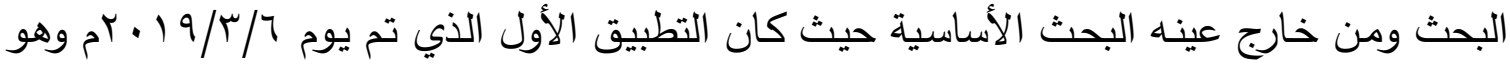
بمثابة الدرجات المستخرجة عند حسـاب "الصدق" ، وللحصول على درجات التطبيق الثاني قامت الباحثة بإعادة تطبيق الاختبار يوم r/T/ 1 ا • rم وذلك بفارق زمني (V) أيام بين التطبيق الأول والتطبيق الثاني.

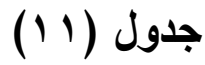

معاملات الارتباط بين التطبيقين الأول والثاني في اختبارات عناصر اللياقة البذنية قيد البحث

\begin{tabular}{|c|c|c|c|c|c|c|}
\hline \multirow{2}{*}{ "ريمة } & \multicolumn{2}{|c|}{ التطبيق الثاني } & \multicolumn{2}{|c|}{ التطبيق الأول } & \multirow{2}{*}{ وحدة القياس } & \multirow{2}{*}{ المتغيرات } \\
\hline & $\varepsilon^{ \pm}$ & 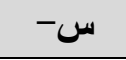 & $\varepsilon^{ \pm}$ & 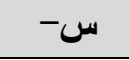 & & \\
\hline *.ArI & rצ.rv & $7 V . .9$ & rA.०० & MI.Yo & الكيلو جرام & إختبار قوة عضلات الرجلين (الديناموميتر) \\
\hline$* . .9 \leq r$ & $0 . r \mu$ & $19.1 \%$ & $7 . .1$ & 18.79 & السنتيمتر & إختبار الوثب العمودي من الثبات \\
\hline$* .901$ & YI.r. & $V V . M I$ & IA.r. & vo.1r & 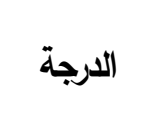 & 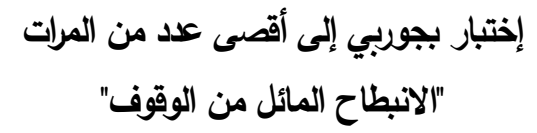 \\
\hline$* . \wedge \vee 1$ & $1 . r \Lambda$ & IT.rs & $1 . r v$ & $1 r . r q$ & 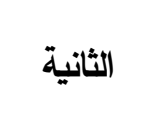 & إختبار الجري المكوكي (ع ×9) أسباق \\
\hline$* .79$. & r.rی & $1 \leq .1$ & Y.YY & Ir.or & 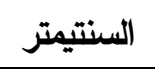 & إختبار ثنى الجذع من الوقوف \\
\hline$* .941$ & $r .11$ & $\Lambda . \varepsilon r$ & $r . .0$ & $V . \varepsilon r$ & 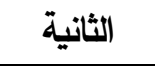 & إختبار الوقوف على مشط القدم \\
\hline$* . .741$ & 0.7 & $V \leq . .7$ & $V .7 V$ & $V Y . \leqslant V$ & 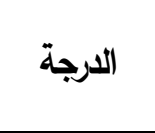 & 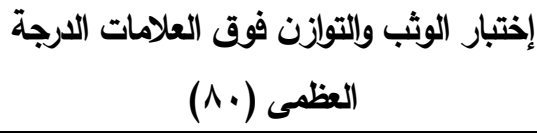 \\
\hline$* \cdot . V \cdot 7$ & $1.7 \mathrm{~V}$ & Ir.Vo & 1.19 & 1r.o. & 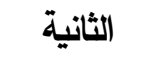 & إختبار الوثب داخل الدوائر المرقمة \\
\hline
\end{tabular}


يتضـح من جدول (1 (1) أن اختبارات عناصر اللياقة البدنية لها درجات ثبات عالية

حيث أسفرت النتائج عن وجود ارتباط بين التطبيقين الأول والثاني.

ب- - اختبار التحصيل المعرفي: (إعداد الباحثة)

يمر اختبار التحصيل المعرفي أثثاء إعداده بمراحل مختلفة حتي يخرج في صورته النهائية

وتتلخص هذه الخطوات فيما يلي:

ا ـ تحديد الهدف من الاختبار

r. إعداد تخطيط عام لمحتوي الاختبار

r. تحديد المادة العلمية:

ـ. تحديد محاور الاختبار

ه. صياغة مفردات الاختبار

7 . إعداد وصياغة المفردات

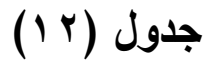

معامل السهولة والصعوبة والتمييز لعبارات الاختبار المعرفي

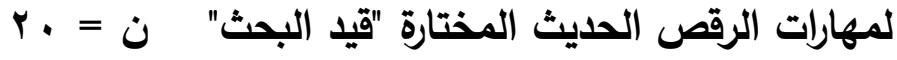

\begin{tabular}{|c|c|c|c|c|c|c|c|}
\hline التمييز & الصعوبة & السهولة & العبارة & التمييز & الصعوبة & السهولة & العبارة \\
\hline..$v_{0}$ & $.0 \%$ &..$\leqslant V$ & rr & $\cdots$ & .0 & .0 & 1 \\
\hline .rr & $.0 \leqslant$ & 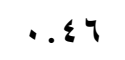 & $r \varepsilon$ & וr.. & . &..$V$. & $r$ \\
\hline.$r r$ &.$r$. &.$\Lambda$. & ro & . r. & سץ. &. $.7 V$ & r \\
\hline . . & $.7 r$ &.$r \Lambda$ & rq & هץ.. & ع & .77 & $\varepsilon$ \\
\hline וr. &. $.7 V$ & rr. & $r v$ & . . &. $.0 \mathrm{~V}$ & •. & 0 \\
\hline سr. & 7. & . $\leqslant 1$ & $r \wedge$ &..$V$ & .71 & . & 7 \\
\hline.$r r$ & 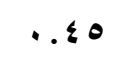 & .00 & rq &..$v 0$ & $.0 r$ &..$\varepsilon V$ & v \\
\hline I.r. & . . . . & .7. & r. & . . & . . &..$V$. & $\wedge$ \\
\hline . . & ع & .977 & r & or. & or. & .70 & 9 \\
\hline..$V 0$ & $.0 Y$ &..$\leqslant V$ & rr & וr.. & $.7 \mathrm{~V}$ & rr. & 1. \\
\hline $.0 r$ & r. & .71 & rr & . . & . rq &. .81 & 11 \\
\hline . vo & س & $.7 \mathrm{~V}$ & & . & . r & .71 & Ir \\
\hline
\end{tabular}




\begin{tabular}{|c|c|c|c|c|c|c|c|}
\hline هץ. . & ט r. & .70 & ro & or. & . \&. & .7. & r \\
\hline rr. & ا & .79 & ד r & . . & 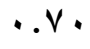 & • . & $1 \varepsilon$ \\
\hline ع س. . & . &..$V$. & $r v$ &.$r V$ & $.1 \varepsilon$ &..$\wedge 7$ & 10 \\
\hline •r. &. $.7 r$ & ג & $\mu \wedge$ &..$\leqslant 1$ & וr. &. .79 & 17 \\
\hline$\ldots V 0$ &.$\Delta \mu$ & 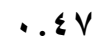 & $r q$ & q.. & $.0 \leq$ & $. .1 \leqslant 7$ & 18 \\
\hline 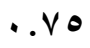 &. .77 & ع س. & $\varepsilon$. & $\because \leqslant V$ & $.0 Y$ &..$\leqslant \wedge$ & 11 \\
\hline ه r. & . . \&Y &..$\diamond \Lambda$ & $\leqslant 1$ &. $.1 \mathrm{~V}$ &.$\vee v$ &.$r o$ & 19 \\
\hline ו".. &. $.7 \mathrm{~V}$ & سץ. & $\leqslant r$ & هץ.. & . . . & .7. & $r$. \\
\hline 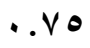 &.$\Delta \mu$ &.$\leqslant V V$ & $\varepsilon r$ & . . Mr & $\cdots \leqslant 0$ & .00 & Y \\
\hline & & & & . . . &..$\leqslant Y$ &..$\Delta \wedge$ & $r Y$ \\
\hline
\end{tabular}

يتضح من جدول (r () أن هناك عدد (r) عبارات لم تحقق الثروط الخاصة لقبولها، ولذلك

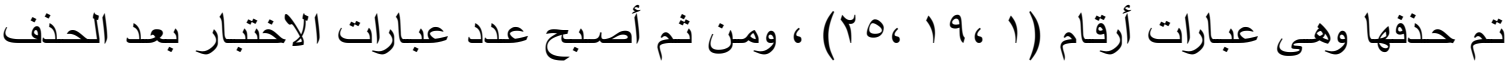

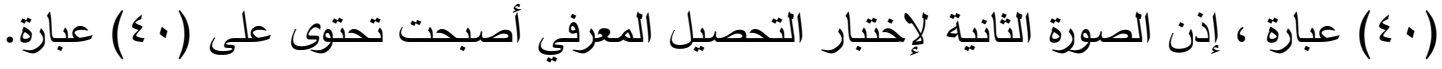
• المعاملات العلمية للاختبار المعرفي.

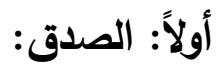

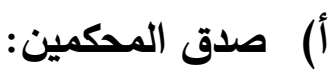

تم عرض المقياس في صورته المبدئية والذي أشتمل علي "ه؛" عبارة وذلك على عدد (0) من السادة الخبراء في قسم التعبير الحركي بكليات التربية الرياضية وقد استخدمت الباحثة حساب النسبة المئوية لآراء الخبراء بهدف استخلاص العبارات الأكثر مناسبة، ولقد قامت الباحثة باختيار العبارات التي حصلت علي نسبه أكثر من • v٪ من آراء الخبراء وتم استبعاد العبارات التي حصلت على نسبه أقل من ذلك وعددهم (r) عبارة وبالتالي أصبح عدد العبارات المقبولة (T؟ ) عبارة موزعين حسب أراء الخبراء على المهارات المختارة قيد البحث. ب) صدق الاتساق الاخلي: تم حساب صدق الاختبار المعرفي باستخدام صدق الاتساق الداخلي بين عبارات كل محور والدرجة الكلية للدحور وكذلك بين درجة كل محور والدرجة الكلية للاختبار وذلك على علي العينة الاستطلاعية والتي بلغت عددها (·r) طالبه من طالبات الفرقة الثانية من نفس مجتمـع 


\section{مجلة نظريات وتطبيقات التربية البدنية وعلوم الرياضة}

البحث وخارج عينه البحث الأساسية وجدولي (T (، ع ( ) يوضحان معاملات الارتباط بين درجة كل عبارة والدرجـة الكليـة للمحور التي تمثله العبارة وكذلك معاملات الارتبـاط بين درجـة كل محور والدرجة الكلية للاختبار

$$
\text { جدول (r) }
$$

معامل الارتباط بين درجة كل عبارة والمجموع الكلى

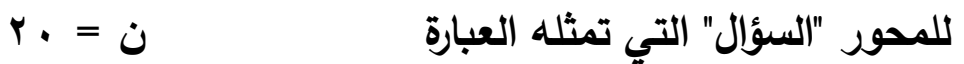

\begin{tabular}{|c|c|c|c|c|c|c|c|}
\hline \multicolumn{2}{|c|}{ السؤال الرابع } & \multicolumn{2}{|c|}{ السؤال الثالث } & \multicolumn{2}{|c|}{ السؤال الثاني } & \multicolumn{2}{|c|}{ السؤال الأول } \\
\hline " ر" & r & " ر" & r & " ر" & r & " ر" & r \\
\hline$* . .797$ & $r V$ & *. . V & 11 & $* . .791$ & $\Lambda$ & $* . V \backslash r$ & 1 \\
\hline$* . V \leq 0$ & $r \wedge$ & *..Vrr & 19 & * & 9 & $* .7 \leqslant 9$ & r \\
\hline$* . \vee Y \wedge$ & $r q$ & $* .7 \vee \varepsilon$ & $r$. & $* . V \leq r$ & 1. & $* . V 1$. & $r$ \\
\hline *. . VY & $r$. & $* . V \cdot 1$ & Y & $* . \times 41$ & 11 & $* . \vee \vee 1$ & $\varepsilon$ \\
\hline$* . V \backslash \varepsilon$ & ו & *. .Vr. & $r r$ & $* .7 \wedge 9$ & Ir & $* . V \leq q$ & 0 \\
\hline$* .799$ & rr & $* .791$ & r & *..VY & r & $* . V \wedge r$ & 7 \\
\hline$* . V . q$ & r & *. . & $r \varepsilon$ & $* . V \leq \varepsilon$ & $1 \varepsilon$ & *. . . & V \\
\hline$* . V \leq 1$ & $r \varepsilon$ & $* . \vee V 4$. & ro & * . . & 10 & & \\
\hline$* . . \vee \vee 0$ & ro & $* .790$ & $r q$ & $* . V \bullet r$ & 17 & & \\
\hline$* . . v \circ r$ & q & & & $* . V V r$ & iv & & \\
\hline$* . \vee \vee 79$ & $r v$ & & & & & & \\
\hline$*, . V \leq \Lambda$ & $\mu$ & & & & & & \\
\hline
\end{tabular}




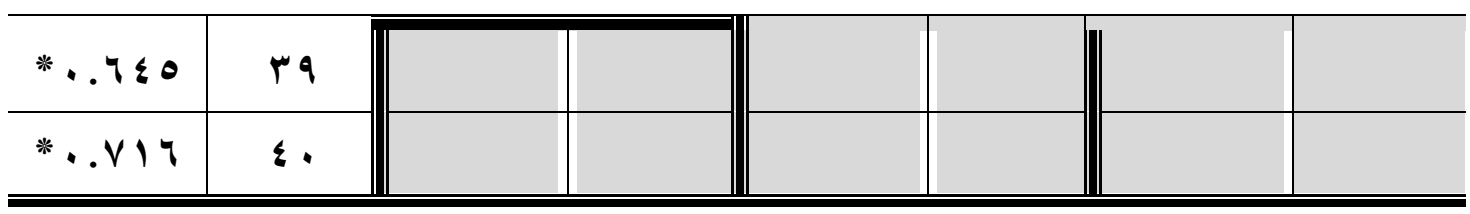

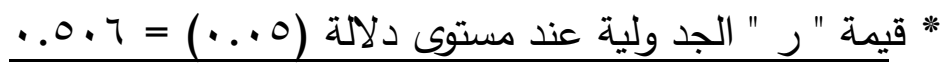

يتضـح من جدول( ( ) وجود ارتباط دال إحصـائي بين درجة كل عبارة والدرجة الكليـة

للسؤال "للمحور" مما يدل على صدق تمثيل العبارة للمحور "للسؤال".

جدول (ء أ)

معامل الارتباط بين درجة كل سؤال والمجموع

\begin{tabular}{|c|c|}
\hline قيمة معامل الارتباط & محاور الاختبار المعرفي \\
\hline * . . VMr & السؤال الأول \\
\hline$* . \vee \vee \neg \varepsilon$ & ال السؤال الثاني \\
\hline$* . . \vee V \varepsilon$ & السؤال الثالث \\
\hline$* . \vee \vee \diamond q$ & السؤال الرابع \\
\hline
\end{tabular}

يتضـح من جدول (ع () وجود ارتباط دال إحصـائي بين درجـة كل محور "سؤال" والدرجـة

الكلية للاختبار المعرفي مما يدل على صدق تمثيل المحاور "الأسئلة" للاختبار .

$$
\text { ج) صدق التمايز : }
$$

تم حساب مُعامل صدق الاختبار المعرفي قيد البحث باستخدام صدق التمايز

$$
\text { جدول (10) }
$$

دلاله الفروق بين الربيع الأعلى والأدنى في اختبار

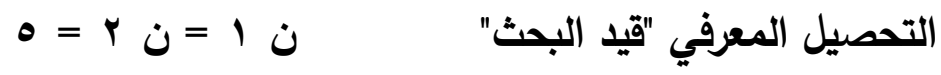




\begin{tabular}{|c|c|c|c|c|c|c|c|}
\hline \multirow{2}{*}{ " قيمة } & \multirow{2}{*}{ الفرق بين } & \multicolumn{2}{|c|}{ الربيع الأدنى } & \multicolumn{2}{|c|}{ الربيع الأعلى } & \multirow{2}{*}{ وحدة القياس } & \multirow{2}{*}{ الاختبار } \\
\hline & & $\varepsilon^{ \pm}$ & س- & $\varepsilon \pm$ & س- & & \\
\hline$* 1 . .9 V$. & 9.0. &..$\Delta r$ & $10 .$. & 1.91 & $r \leq .0$. & زمن & اختبار التحصيل المعرفي \\
\hline
\end{tabular}

يتضـح من جدول (0 1) أن قيمـة "ت" المحسوبة أكبر من قيمـة "ت" الجدولية عند مستوى معنويـة (0 . • ) بين متوسطي (الربيع الأعلى ، الربيع الأدنى) ولصسالح متوسط الربيع الأعلى في اختبار التحصيل المعرفي قيد البحث ، مما يدل على صدق هذه الاختبارات. ثانياً: الثبات:

أ) بات الاختبار باستخدام معامل ألفا تم حساب معامل ثبات الاختبار المعرفي باستخدام معامل " ألفا "وفقاً لتعديل كرونباخ.

$$
\text { وجدول ( • ب) يوضح قيم معاملات الثبات. }
$$

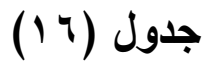

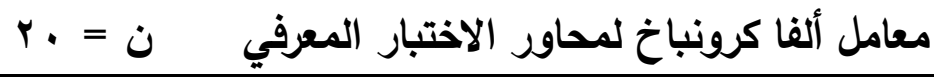

\begin{tabular}{|c|c|c|}
\hline قيمة معامل ألفا & عدد العبارات & محاور الاختبار المعرفي \\
\hline$* . . \vee r q$ & v & السؤال الأول \\
\hline$* . . \vee V r$ & 1. & السؤال الثاني \\
\hline$* . \vee \vee \wedge \varepsilon$ & 9 & السؤال الثالث \\
\hline *..VTV & $1 \varepsilon$ & السؤال الرابع \\
\hline
\end{tabular}

* قيمة "ر " الجد ولية عند مستوى دلالة (0. . . ) = ب .0.

يتضح من جدول (7 ( ) أن جميع محاور الاختبار المعرفي تتمتع بقيم عالية لمعامل ألفا مما

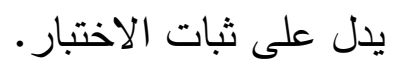$$
\text { r } 1 \text { - تحديد الزمن اللازم للاختبار: }
$$

جدول (iv)

\begin{tabular}{|c|c|c|c|}
\hline \multirow{2}{*}{ الزمن المناسب } & \multirow{2}{*}{ المجموع } & \multicolumn{2}{|c|}{ الزمن التجريبي } \\
\hline & & أخر طالبة & زمن إجابة أول طالبة \\
\hline
\end{tabular}

المتوبط الحسابي لزمن اختبار التحصيل المعرفي 


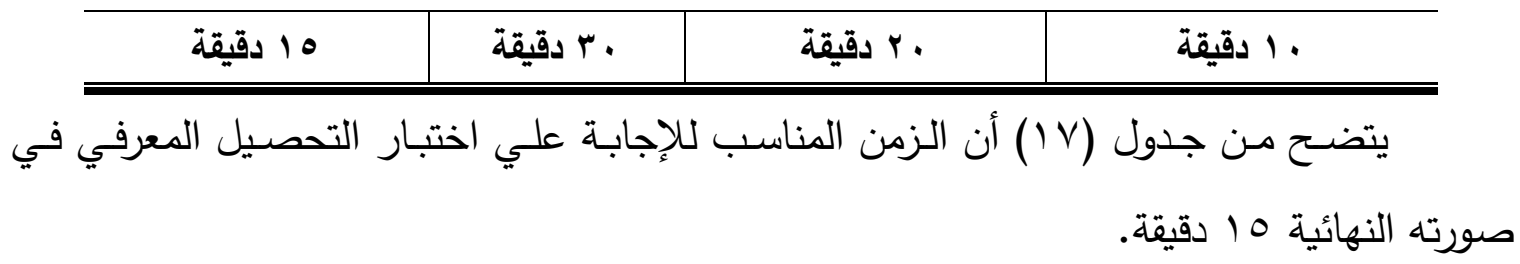$$
\text { ج- اختبار القدرات العقلية لقياس مستوي الاككاء: }
$$

استخدمت الباحثة اختبار الذكاء اللفظي للمرحلة الثانويـة والجامعية الذي قام بإعداده " جابر

$$
\begin{aligned}
& \text { عبد الحميد جابر ، محمود أحمد عمر"( ب99 (م). } \\
& \text { المعاملات العلمية لاختبار الأكاء : } \\
& \text { أولاً: صدق و ثبات الاختبار: }
\end{aligned}
$$

\begin{tabular}{|c|c|c|c|c|c|c|c|}
\hline \multirow{2}{*}{ " قيمة " " " } & \multirow{2}{*}{ الفرق بين } & \multicolumn{2}{|c|}{ الربيع الأدنى } & \multicolumn{2}{|c|}{ الربيع الأعلى } & \multirow{2}{*}{ وحدة } & \multirow{2}{*}{ الاختبار } \\
\hline & & $\varepsilon^{ \pm}$ & س- & $\varepsilon \pm$ & س- & & \\
\hline * q.००r & $1 \wedge .0 \ldots$ & E.rq & $\vee \wedge .0 \ldots$ & 1.10 & $9 \vee \ldots$ & زمن & اختبار الذكاء \\
\hline
\end{tabular}

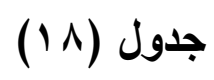

دلاله الفروق بين الربيع الأعلى والأدنى في

$$
\begin{aligned}
& \text { اختبار الأكاء "قيد البحث" } \\
& 0=r \dot{0}=1 \text { ن }
\end{aligned}
$$

\begin{tabular}{|c|c|c|c|c|c|c|}
\hline \multirow{2}{*}{ "ريمة } & \multicolumn{2}{|c|}{ التطبيق الثاني } & \multicolumn{2}{|c|}{ التطبيق الأول } & \multirow{2}{*}{ وحدة القياس } & \multirow{2}{*}{ المتغير } \\
\hline & $\varepsilon \pm$ & س- & $\varepsilon^{ \pm}$ & س- & & \\
\hline$* . \wedge \varepsilon r$ & 1.7. & $\Lambda \Lambda . \mid r$ & $V . \varepsilon q$ & $\wedge \Lambda . \wedge r$ & زمن & اختبار الذكاء \\
\hline
\end{tabular}

يتضح من جدول (1 (1) أن قيمة "ت" المحسوبة أكبر من "ت" الجدولية عند مستوى معنويـة

$$
\cdot(\cdot \cdot 0)
$$

$$
\text { جدول (19) }
$$

معاملات الارتباط بين التطبيقين الأول والثاني في اختبار الأكاء قيد البحث ن = . r 
يتضح من جدول (9 1 ) أن اختبار الذكاء لها درجات ثبات عالية حيث أسفرت النتائج

عن وجود ارتباط بين التطبيقين الأول والثاني.

خامساً: البرنامج التعليمي المقترح:

\section{رابعاً :البرنامج التعليمي باستخدام الرحلات المعرفية :}

تعتبر الرحلات المعرفية باستخدام شبكة الانترنت هي الدحور الرئيسي الذى يدور حوله

هذا البحث وقد قام أحد المتخصصين في تكنولوجيا التعليم بإنتاج البرنامج المقترح , فعملية إعداد برنامج تعليمي قائم على استخدام الكمبيوتر وشبكة الانترنت ليست عملية سهلة بل هي عملية غاية

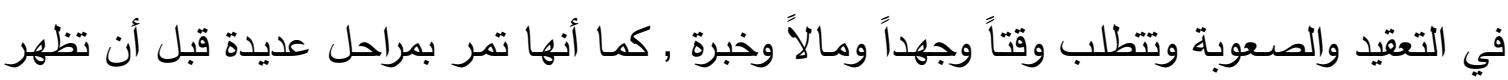
بالصورة التي نراها عليها ويتضمن إعداد البرنامج الخطوات التالية :

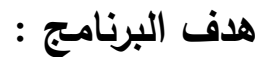

تأثير إستخدام الرحلات المعرفية على التحصيل المعرفي ومستوى اداء الرقص الحديث , وينبثق منه الأهداف التالية :- - هدف عام معرفي : ويتمثل في إكساب الطالبات بعض المعلومات عن معارف وحقائق ومفاهيم وقوانين مرتبطة بالرقص الحديث قيد البحث . - - هدف عام مهاري : ويتمثل في إكساب الطالبات كيفية الأداء الفني للرقص الحديث قيد البحث. - ترجمة الأهداف العامة للبرنامج وصياغتها في صورة سلوكية إجرائية : تم تحديد الأهداف لكل هدف عام علي حده , وصياغتها في شكل سلوك نهائي يمكن ملاحظته وقياسه أي يجب أن يدل الهدف علي وصف النتيجة التي يجب أن تكون عليها التلميذة عند تعلم بعض المهارات الأساسية في الرقص الحديث قيد البحث , ونتيجـة مـروره بـالنواحي التعليميـة المحددة والتي يجب أن يكتسبها مـن خـلاد البرنـامج التعليمي الذي يستخدم الرحلات المعرفية وقد تم تحديد الأهداف السلوكية الإجرائية في أهداف معرفية وأهداف مهارية. الأهداف السلوكية المعرفية :

- أن تتعرف الطالبات علي النقاط الفنية للأداء الرقص الحديث قيد البحث . - - أن تتذكر الطالبات الخطوات التعليمية للأداء الفني الرقص الحديث قيد البحث . 
- أن تتعرف الطالبات علي طريقة الأداء المثالي من خلال الأداء الفني الرقص الحديث . أسس بناء البرنامج باستخدام الرحلات المعرفية: تمت مراعاة مجموعة من الأسس العلمية عند بناء البرنامج وكانت علي النحو التالي :

- أن تراعي خصائص نمو الطالبات في هذه المرحلة . - أن يحقق محتواه تكامل الثخصية من خلال علاقة الطالبات مع ذاته ومع الآخرين - أن يراعي حسن توزيع الحمل بين النشاط والراحة . - أن يراعي عوامل الأمان حرصاً علي سلامة الطالبات . - أن يتناسب محتواه مع أهداف البرنامج -

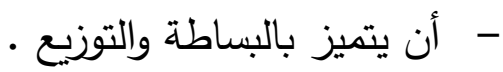

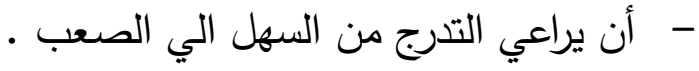

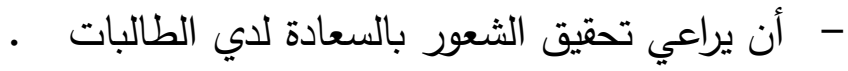
تحديد محتوي الرحلات المعرفية:

تتكون الرحلات المعرفية من عدة عناصر تتكامل وتترابط فيما بينها للوصول الىى لـى لـ مستوى التعلم عن طريق الإبحار عبر شبكة الإنترنت ويتحقق الهدف العام منها لمعرفـة مدى فاعليتها على التحصيل المعرفي ومستوى اداء الرقص الحديث .

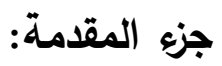

يشمل الجزء الأول على العنوان والمقدمة و تكون بأسلوب جذاب وشيق وتعطى فكرة عامة عن الموضوع وتعرفه بأهم مكوناته والهدف من المقدمة إثارة اهتمام الطالبات وتثجيعه على بلى دراسة المهارة قيد البحث واكتسبا التحصيل المعرفي , وتعليماتها بالنسبة للمتعلم وأهدافها ويتضمن هذا العنصر صياغة الأهداف في صورة سلوكية واضحة ومختصرة تصف السلوك النهائي المتوقع

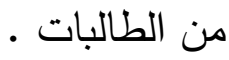

جزء المحتوى التعليمي : - ( 
تم مشـاهدة الـرحلات المعرفيـة بالبرنـامج داخـل معدـل الحاسـب الألكى بكليـة التربيـة الرياضية جامعة مدينة السادات وقامت الباحثة بتحديد المهارة المراد تعلمها للطالبات في مستوى الأداء في الرقص الحديث , وقامت بالمتابعة والتوجيه وتصحيح الأخطاء للطالبات وبعد ذلك يتحكم تحكماً تامـاً وبحريـة في السرعة والمسـار والتتابع , وتحتوى على قدر من المعلومـات العلمية التي تؤدى في نهاية التعلم الى خلفية معرفية متكاملة لدى الطالبات ومن خلال التغذية الراجعة يمكن ان يعرف الطالبات هل يمكن الانتقال الى الخطوة التالية أم يكرر تلك المهارات مرة آخرى وسائل الاتصال التعليمية والتكنولوجية : اشتملت وسائل الاتصـال التعليمية والتكنولوجية على الهيب ميديا الخاصـة بالبرنامج التعليمي من خلال شبكة الانترنت الخاصة بمراحل تعليم المهارة قيد البحث .

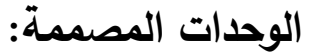

وهى وحدات مصممة تساعد الطالبات على تعلم المهارة قيد البحث بنفسها من خلال الرحلات المعرفيـة , وتمـده بالتعليقـات والمعلومـات المتتوعـة عن هـف الوحدة ومحتواهـا والتغذيـة الراجعة لمعرفـة الأداء الصحيح من الخاطئ من خـلال الموقع الإلكتروني للرحلة المعرفية الخاصـة بالبحث .

\section{تحديد صفحات البرنامج :}

تم تحديد محتويـات البرنـامج في ضـوه الهدف العـام والأهداف السـلوكية لا لـرقص الحديث , كما تم اختيار المعلومـات المعرفية المرتبطة بالرقص الحديث قيد البحث , وتم تمثل

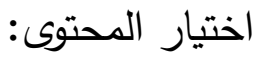
مقدمة شاملة عن الرقص الحديث مقايث المهام الخاصة بالرقص الحديث قيد البحث . الخطوات التعليمية للمهارة قيد البحث . التسلسل الحركي للمهارة قيد البحث . الأخطاء الشائعة للمهارة قيد البحث . 
المصادر التي تحتوى عمليات البحث للاستعانة بها في جمع البيانات .

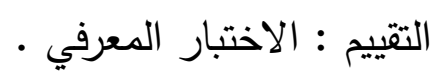
الخاتمة : توضيح للطالبات ارسال التعليقات والأفكار والآراء . تصديد الأنثطة التعليمية : أنثطة تقوم بها الباحثة :

• قبل البدء في تدريس البرنامج : تقوم بتوضيح مكونات الحاسب الألى وكيفية إستخدام ملحقاته وكيفيه العمل بالبرنامج ,إرساء الرابط الخاص بالموقع لللخول لأداء عملية الإبحار •

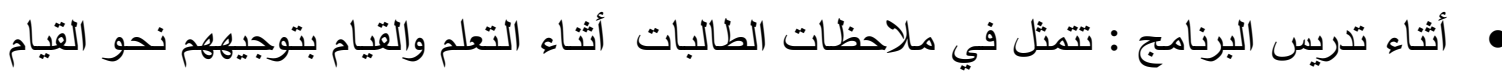
بالأنشطة التعليمية ومتابعة تقدمه وتصحيح أخطائهم التتفيذية والإجابة على التساؤلات التي قد تثار أثناء استخدامهم للرحلة المعرفية . بعد الانتهاء من تدريس البرنامج : تتحدد في تكليف الطالبات بالقيام بالأداء المطلوب والذى لهـ يتمثل في الخطوات التعليمية المتدرجة من البسيط الى المركب ومن السهل الى الصعب . أنشطة تقوم بها المتعلم (الطالبات): تتمثل في إستخدام المتعلم للرحلة المعرفية والسير بداخلها .

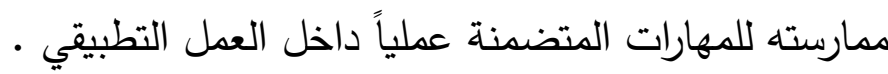
العمل الجماعي والقيام بجمع المعلومات عن المهام الخاصة بالمهارة قيد البحث . طريقة تقويم البرنامج : - مان

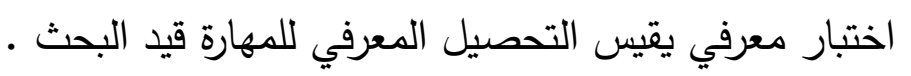
تصميم إستمارة مقننة لقياس الأداء المهارى للمهارة قيد البحث . إعداد الصورة المبدئية للبرنامج وعرضه على مجموعة من الخبراء . بعد الانتهاء من إعداد البرنامج تم عرضه على مجموعة من الخبراء المتخصصين في المناهج وطرق التدريس وذلك لإستطلاع رايهم حول :

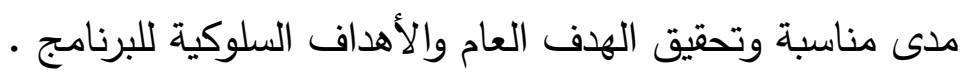
• الدقة العلمية والوضوح لمحتوى البرنامج • 


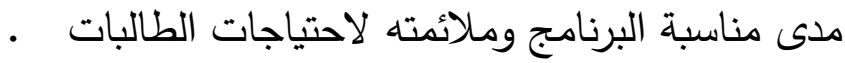

مدى مناسبة أساليب التقويم المستخدمة وصلاحية البرنامج للتطبيق •

الصورة النهائية للبرنامج :

مـن خـلال اسـتعراض آراء الخبـراء وتحليلهـا واتضـح مـوافقتهم على صــلاحية البرنـامج

للتطبيق.

\section{الإطار الزمنى اللبرنامج التعليمي المقترح}

قامت الباحثة بإعداد إستمارة لإستطلاع راي الخبراء لتحديد الفترة الزمنية اللازمة لتنفيذ

البرنامج التعليمي المقترح , وجدول (·r) يوضح آراء السادة الخبراء في تحديد الفترة الزمنية اللازمة لتنفيذ البرنامج التعليمي المقترح.

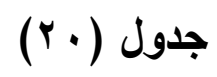

نتائج إستطلاع أىى الخبراء حول تحديد الفترة الزمنية لأجزاء

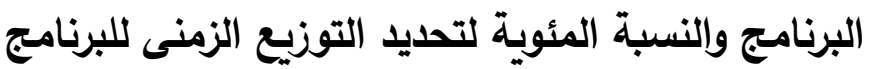

\begin{tabular}{|c|c|c|c|c|c|}
\hline المختار & | النسبة المئوية & 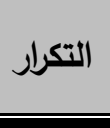 & المقترحات & محتوي البرنامج المقترح & م \\
\hline$\sqrt{ }$ & $\%$ & 1. & أسابيع (شهر ونصف) & \multirow{3}{*}{ تحديد الفترة الكلية للبرنامج } & \multirow{3}{*}{1} \\
\hline & $\%$ & 0 & 1أسابيع (شهرين) & & \\
\hline & $\%$. & $\varepsilon$ & • (أسابيع(شهرين) ونصف) & & \\
\hline$\sqrt{ }$ & $\%$ & 1. & وحتان & \multirow{3}{*}{ تحديد عدد الوحدات التعليمية } & \multirow{3}{*}{ r } \\
\hline & $\%$ & ○ & r ب وحدات & & \\
\hline & $\%$ \%. & $r$ & ؛ وحدات & & \\
\hline & $\%$ \%. & $\varepsilon$ & 0 ؛ دقيقة & \multirow{3}{*}{ خلال البرنامج التعليمي } & \\
\hline & $\%$ r. & r & . بادقيقة & & $r$ \\
\hline$\checkmark$ & $\% 1 \ldots$ & 1. & ـ 9 دقيقة & & \\
\hline
\end{tabular}


يتضـح مـن جدول (·r) نتائج اسـتطلاع الخبـراء حول تحديد الفترة الزمنيـة لأجزاء البرنـامج والنسبة المئويـة لتحديد التوزيـع الزمنى للبرنـامج حيث ارتضـت الباحثة بنسبة مئويـة قدرها ( • (\%أكثر من آراء الخبراء في التوزيع الزمنى للبرنامج , وقد أسفرت النتائج الاتي : • الفترة الكلية للبرنامج : جأسابيع (شهر ونصف). • الوحدة التعليمية اليومية خلال الأسبوع الواحد : (Y) وحدة . زمن الوحدة التعليمية اليومية في الأسبوع الواحد : ( • (9) دقيقة .

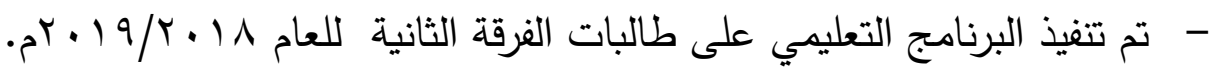
- - عدد الأسابيع الخاصة بتطبيق المحتوى التعليمي بلغ (T) أسابيع. - تم تحديد عدد الوحدات التعليمية اليومية خلال الأسبوع بواقع (Y) وحدتان تعليميتان. - تقـوم الباحثة بمتابعـة المجموعـة التجريبيـة والتوجيـهـ والإشـراف عليهـا خـلال التطبيـق العملي للوحدات التعليمية قيد البحث.

\section{خامساً: الاراسة الاستطلاعية:}

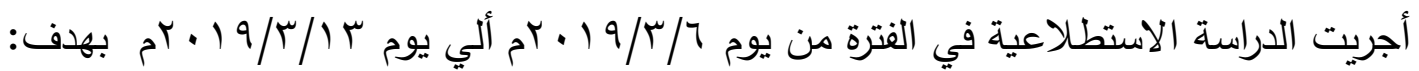
التأكد من سهولة القياسات اختيار الأماكن المناسبة لإجراء القياسات تحديد زمن إجراء القياسات التأكد من المعاملات العلمية للاختبارات (الصدق - الثبات). التأكد من مدى ملائمة الاختبارات والقياسات المستخدمة. •التعرف على مدى صلاحية الأدوات والأجهزة المستخدمة قيد البحث. سادساً: الإجراءات التنفيذية للبحث :

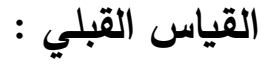

قامت الباحثة بإجراء القياس القبلي علي عينة البحث الأساسية في إختبار التحصيل المعرفي ومستوى أداء الرقص الحديث قيد البحث , وذلك في يومي 7 19/T/ 1 ـ م م . 
تنفيذ البرنامج التعليمي :

قامت الباحثة بتطبيق البرنامج التعليمي المقترح باستخدام الرحلات المعرفية في صورته

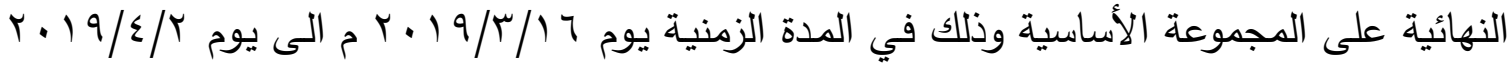

م وبواقع وحدتين تعليمية أسبوعيا , وبلغ زمن الوحدة التعليمية ( .9) دقيقة .

القياسات البعدية:

بعد الانتهاء من تطبيق البرنامج التعليمي المقترح تم إجراء القياس البعدي في اختبار التحصيل المعرفي و مستوى الأداء في الرقص الحديث قيد البحث، وذلك يوم ؟/ء/9 ا • ب م سابعاً: المعالجات الإحصائية:

قامــت الباحثـة باستخــدام القـوانين الإحصـائية وكـلكك الحاسـب الآلكي باســخدام البرنـامج

الإحصـائي "SPSS" وتم حساب مـا يلي : المتوسط الحسابي - الوسيط - الانحراف المعياري . معامل الالتواء -اختبار دلالـة الفروق (ت) - معامـل الارتباط وارتضـت الباحثة بمستوي معنويـة

\section{عرض النتائج ومناقشتها} أولاً: عرض ومناقشة نتائج الفرض الأول.

ا ـ عـرض نتائج المجموعـة الضـابطة في مستوى الأداء المهاري "لمهـارات الرقص الحديث

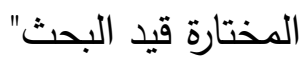

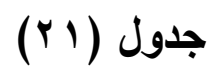

دلالة الفروق بين متوسطي القياسيين القبلي والبعدي ونسب التغير للمجموعة

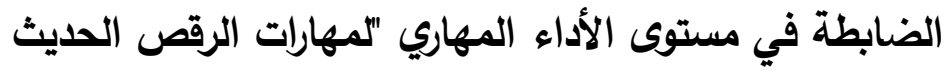

$\bullet \cdot=\dot{0}$ المختارة قيد البحث"

\begin{tabular}{|c|c|c|c|c|c|c|c|c|}
\hline \multirow{2}{*}{ التغير } & \multirow{2}{*}{ " قيمة " } & \multirow{2}{*}{ الفرق بين } & \multicolumn{2}{|c|}{ القياس البعدي } & \multicolumn{2}{|c|}{ القياس القبلي } & \multirow{2}{*}{ المتغيرات المهارية } & \multirow[t]{2}{*}{$\hat{r}$} \\
\hline & & & $\varepsilon^{ \pm}$ & سس & $\varepsilon \pm$ & سس & & \\
\hline $\begin{array}{c}0 \leq .1 \\
V\end{array}$ & $\begin{array}{c}1 r . q \\
r\end{array}$ & r.V. & $1 . \leqslant 7$ & T. & .07 & $r .1 \mu$ & الممشى & .1 \\
\hline $0 . .1$ & IV.V & r.o. & $\cdots 9$. & $\neg . \wedge \wedge$ & 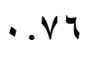 & $r . r \Lambda$ & الجري &.$r$ \\
\hline
\end{tabular}




\begin{tabular}{|c|c|c|c|c|c|c|c|c|}
\hline v & $r$ & & & & & & & \\
\hline $\begin{array}{c}09 . \\
.\end{array}$ & $\vee . \bullet \wedge$ & $1 . \wedge \varepsilon$ & $1 . \mu$ & $0.1 \%$ &. .87 & r. rq & الحجل & r \\
\hline $\begin{array}{c}r 7.9 \\
9\end{array}$ & $7.0 \mathrm{~V}$ & 1.90 & 1.1. & $\varepsilon .7 \mu$ &.$V \mu$ & r.rA & الارتداء &.$\varepsilon$ \\
\hline $\begin{array}{c}\varepsilon 1.9 \\
7\end{array}$ & $\begin{array}{c}18.1 \\
r\end{array}$ & r.. &. .99 & 7. Yo & $\cdot .87$ & r.19 & النجمة & .0 \\
\hline $\begin{array}{c}r V . r \\
0\end{array}$ & 7.11 & 1.11 &..$\vee 7$ & $\varepsilon . \mu r$ & $\cdot . \Lambda$. & r.10 & الغزالة & .7 \\
\hline $\begin{array}{c}\varepsilon .1 \\
\Lambda\end{array}$ & $\begin{array}{c}\text { Y. Y } \\
.\end{array}$ & Y.o. &..$\Lambda \wedge$ & $0 . \vee 9$ &. .79 & r.Yq & الموزة &.$v$ \\
\hline $\begin{array}{c}\text { rq. } \\
v\end{array}$ & $\begin{array}{c}1 . .7 \\
1\end{array}$ & r.Ir & $.9 r$ & ט & $\cdot . \varepsilon \varepsilon$ & Y.YI & الفجوة &.$\Lambda$ \\
\hline $\begin{array}{c}\varepsilon \varepsilon . V \\
7\end{array}$ & $\begin{array}{c}19 . \varepsilon \\
r\end{array}$ & Ү.7० &.$\vee \vee \wedge$ & $0.9 r$ & - $\leq 9$ & r.YV & وثبة الحصان & .9 \\
\hline $\begin{array}{c}\mu . V \\
r\end{array}$ & $\begin{array}{c}\text { IY.A } \\
1\end{array}$ & $r . . r$ & 1.1 & $0 . \mu \wedge$ &. $.7 r$ & o & الزحلقة & 1. \\
\hline $\begin{array}{c}-9.9 \\
7\end{array}$ & $\begin{array}{c}11.0 \\
\varepsilon\end{array}$ & Y. Yo &..$\Lambda \wedge$ & $0.7 \mu$ &..$\circ r$ & $\mu . \mu \Lambda$ & حركات التكور والمد & 11 \\
\hline $\begin{array}{l}Y V . r \\
\Lambda\end{array}$ & $9 . \leqslant 9$ & 1.41 &.$\Delta \mu$ & $\varepsilon . \varepsilon Y$ &. $.7 r$ & Y.Y & حركات التوزان من الثبات & ir \\
\hline pq. & $\begin{array}{c}17.9 \\
V\end{array}$ & I.r &. .77 & $\varepsilon . \diamond \varepsilon$ &. $.7 \mathrm{~V}$ & Y.Y & حركات التوزان من & 1r \\
\hline
\end{tabular}

يتضح من جدول (Yr) وجود فروق دالة إحصائياً بين متوسطي القياسيين القبلي والبعدي للمجموعة الضـابطة في مستوى الأداء للمتغيرات المهارية المختارة "قيد البحث" كما يتضح أيضـاً وجود نسب تغير بين القاسيين القبلي والبعدي ولصالح متوسط القياس البعدي. r. مناقشة نتائج عرض نتائج المجموعة الضابطة في مستوى الأداء المهاري "لمهارات الرقص الحديث المختارة قيد البحث" لعثل 
يتضـح من جدول (Y) وجود فروق دالة إحصـائياً بين متوسطي القياسيين القبلي والبعدي للمجموعة الضـابطة في مستوى الأداء للمتغيرات المهاريـة المختارة "قيد البحث" ، حيث كانت قيمـة "ت" الجدولية عند مستوى معنويـة(0 . . ·) أقل من قيمـة "ت" المحسوبة والتي انحصـرت مـا بين

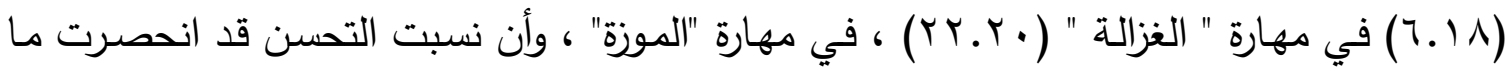

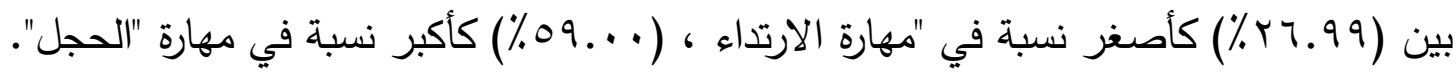

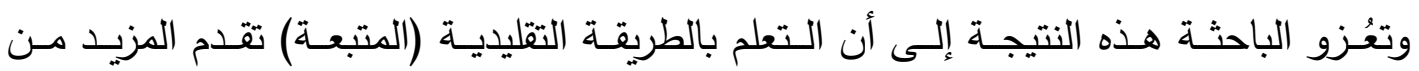
المعلومات الجديدة والمتنوعة وممارسة المتعلمين للمهارات المختارة "قيد البحث" ومعرفتهن لمضمون الأداء الخاص بالمهارات وذلك من خلال الشرح اللفظي والمعلومات التي تساعد على تكوين الصورة الواضحة لتلك المهارات.

كمـا أن هذا التقدم ربمـا يرجـع إلى ممارسـة الطالبـة عمليـاً للمهارات المختارة "قيد البحث" ومعرفة مضمون الأداء الخاص بكل مهارة من خلال الثرح اللفظي للمعارف والمعلومات المرتبطة بالمهارات والأنماط السلوكية الواجب توافرها لدى الطالبة بالإضـافة إلى النموذج أو العرض العملي للمهارة، مع قيام الطالبة بأداء المهارة وممارستها وما يصساحب ذلك من تدعيم للأداء المهارى عن طريق المعلمة أو تصحيح الأخطاء، حيث يساعد ذلك على تكون صورة واضحة لتلك المهارات. كما تعُزو الباحثة سبب ذلك التقدم لدى المجموعة الضابطة إلى جدوى الطريقة التقليدية التي لا يمكن إغفالها والتي تعتمد على تلقى المتعلمة للمعلومات والمفاهيم من المعلمة، حيث قيام المعلمة بشرح المهارة وعرض نموذج لها والتدرج في عملية تقديم التغذية الراجعة خلال كل مرحلة من مراحل التعليم.

ومن خلال ما سبق يتضـح أن الطريقة التقليدية المتبعة (الثرح والعرض) لها تأثير إيجابي على مستوى التحصيل المعرفي ومستوى أداء المهارات المختارة "قيد البحث" ............ وتتفق هذه النتائج مع نتائج الكثير من الدراسات التي أشرات إلى تأثير الطريقة التقليدية على مستوى التحصيل المعرفي والمهارى لدى المتعلمين. ويتفق ذلك مع نتائج دراسات كل من "'أسامة محمد عبد العزيز" ( ( . . rم) (Y) ، "السيد يسن مرزوق" ( • ( • م) (r) في أن الطريقة التقليدية التي لها تأثير في جوانب التعلم ولكن بنسبة أقل. 
ץ. عرض نتائج المجموعة الضابطة في مستوى التحصيل المعرفي "لمهارات الرقص الحديث

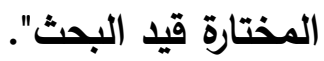

$$
\text { جدول (Yr) }
$$

دلالة الفروق بين متوسطي القياسيين القبلي والبعدي ونسب التغير للمجموعة الضابطة في

\begin{tabular}{|c|c|c|c|c|c|c|c|}
\hline \multirow{2}{*}{ نسبة } & \multirow{2}{*}{ " قيمة " } & \multirow{2}{*}{ المترق بين } & \multicolumn{2}{|c|}{ القياس البعدي } & \multicolumn{2}{|c|}{ القياس القبلي } & \multirow[b]{2}{*}{ المتغيرات } \\
\hline & & & $\varepsilon^{ \pm}$ & س- & $\varepsilon^{ \pm}$ & س- & \\
\hline צ & rr.si & $11.1 \mathrm{r}$ & 9.79 & $r . r o$ & r.7. & 19.14 & اختبار التحصيل \\
\hline
\end{tabular}

مستوى التحصيل المعرفي "لمهارات الرقص الحديث المختارة قيد البحث" ن= •

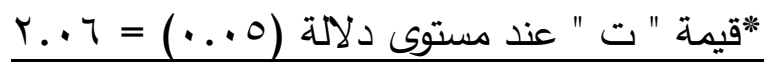

يتضـح من جدول (Yr) وجود فروق دالة إحصـائياً بين متوسطي القياسيين القبلي والبعدي للمجموعة الضابطة في مستوى التحصيل المعرفي ولصالح متوسط القياس البعدي. ع ـ مناقشة نتائج المجموعة الضابطة في مستوى التحصيل المعرفي "'مهارات الرقص الحديث

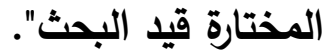

يتضـح من جدول (YY) وجود فروق دالة إحصـائياً بين متوسطي القياسيين القبلي والبعدي للمجموعة الضابطة في مستوى التحصيل المعرفي لمهارات الرقص الحديث قيد البحث حيث كانت

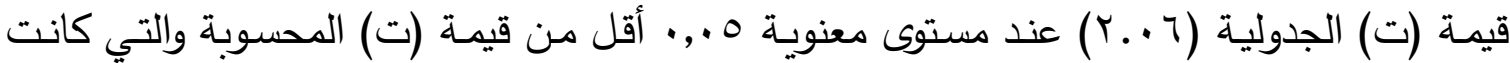

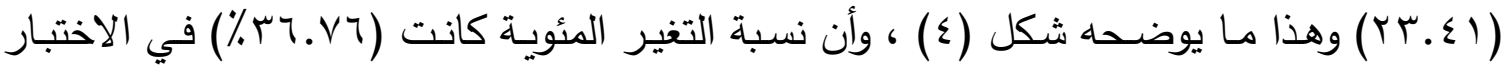
المعرفي لمهارات الرقص الحديث قيد البحث. وترجع الباحثة هذه الفروق إلى أن المعلم في الطريقة التقليدية (الثرح اللفظي وأداء النموذج العملي) يقدم المزيد من المعلومات الجديدة والمتتوعة حول المهارات قيد البحث كما يقدم معلومات عن الأخطاء الثـائعة التي قد تحدث أثناء الأداء وكذلك يوضـح لهم مراحل الأداء والنواحي الفنية التي يجب مراعاتها أثناء الأداء وبالتالي فأن أي معلومات تقدم للطالبات سوف تزيد من حصيلتهن المعرفية وتجعل هنالك تقدم في مستوى التحصيل المعرفي بين القياس القبلي والبعدي لصـالح القياس البعدي. 


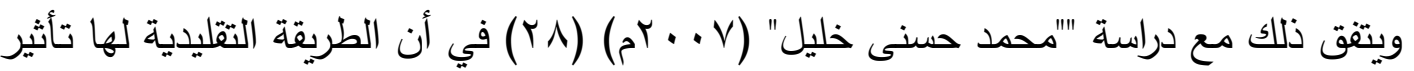
في جوانب التعلم ولكن بنسبة أقل. وبذلك يكون قد تحقق صحة ما جاء بالفرض الأول من فروض البحث والذي ينص على: " وجود فروق دالة إحصائياً بين متوسطي القياسيين القبلي والبعدي للمجموعة الضـابطة في مستوى الأداء للمتغيرات المهاريـة المختارة "قيد البحث" ومستوى التحصيل المعرفي ولصالح متوسط

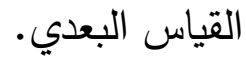
ثانياً: عرض ومناقثة نتائج الفرض الثاني. 1. عرض نتائج المجموعة التجريبية في مستوى الأداء المهاري "لمهارات الرقص الحديث

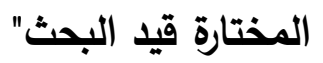

$$
\text { جدول (Yr) }
$$

دلالة الفروق بين متوسطي القياسيين القبلي والبعدي ونسب التغير للمجموعة

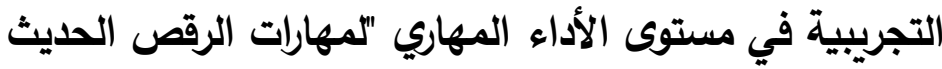

$$
\text { ○. = ن }
$$

\begin{tabular}{|c|c|c|c|c|c|c|c|c|}
\hline \multirow{2}{*}{ ن التغبر } & \multirow{2}{*}{ " ق " " " } & \multirow{2}{*}{ الفرق بين } & \multicolumn{2}{|c|}{ القياس البعدي } & \multicolumn{2}{|c|}{ القياس القبلي } & \multirow{2}{*}{ المتغيرات المهارية } & \multirow[t]{2}{*}{ p } \\
\hline & & & $\varepsilon^{ \pm}$ & سس & $\varepsilon^{ \pm}$ & سس & & \\
\hline$\%$. . or & Y0.11 & $\{. \wedge 9$ & .94 & $\wedge . . \wedge$ &.$V r$ & $r .19$ & الممشى & .1 \\
\hline$\%$ \%. O V & rr.oq & $\varepsilon . \wedge V$ &.$v 0$ & ^.. $\varepsilon$ &. $.7 V$ & $r .1 \mathrm{~V}$ & الجري &.$r$ \\
\hline$\% \pi 1 . . v$ & YY.q0 & $\varepsilon .91$ &.$\wedge 7$ & ^.. \& & $\cdots \leqslant r$ & $r .1 r$ & الحجل &.$r$ \\
\hline \% & r & $0 . .7$ & .71 & A.ro &. .00 & $r .19$ & الارتداء &.$\varepsilon$ \\
\hline$\% 71 . .7$ & Yo.. $\varepsilon$ & $\varepsilon . \wedge 7$ &. .11 & $v .97$ & $\cdot . \leqslant Y$ & r.l. & النجمة & .0 \\
\hline$\%$ \%.91 & rr.qr & 0.19 & .71 & A.ro &. .71 & r.. & الغزالة & .7 \\
\hline$\%$ \%.rV & Yo. $\{1$ & $\leq .9$. & .71 & $\Lambda .1 \mu$ & $\because v 1$ & $r . r r$ & الموزة &.$v$ \\
\hline 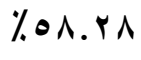 & YV.Is & $\{.0 \leqslant$ & $\cdot . \vee \wedge$ & $v . v q$ & $\cdot . \leqslant Y$ & r.Yo & الفجوة الفوة &.$\wedge$ \\
\hline \% & $r \leq .11$ & $0 . .7$ & .04 & A. ro & $\cdot . \leqslant \wedge$ & 4.19 & وثبة الحصان & .9 \\
\hline
\end{tabular}

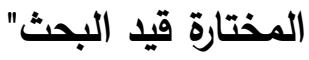




\begin{tabular}{|c|c|c|c|c|c|c|c|c|}
\hline$\%$ ० . $\leqslant \vee$ & $r r . \varepsilon r$ & $\varepsilon . V_{1}$ &.$V r$ & $V . q r$ & . .47 & r.M & الزحلقة & 1. \\
\hline$\%$ \%I.rY & 91.11 & $0.1 r$ & $\therefore \leqslant 9$ & $\Lambda . r \wedge$ & 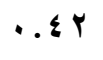 & r.ro & حركات التكور والمد & 11 \\
\hline$\% \neg \cdot . \wedge \wedge$ & rr.oq & $\varepsilon . \wedge V$ &. .74 & ^... & $.0 \leqslant$ & $r .1 r$ & حركات التوزان من & Ir \\
\hline \%rr.vr & $00.0 \mathrm{r}$ & 0.10 &. .01 & A.r. & .07 & r.. T & حركات التوزان من & in \\
\hline
\end{tabular}

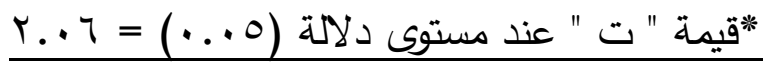

يتضـح من جدول (Tr) وجود فروق دالة إحصائياً بين متوسطي القياسيين القبلي والبعدي للمجموعة التجريبية في مستوى الأداء للمتغيرات المهاريـة المختارة "قيد البحث" كمـا يتضح أيضـاً وجود نسب تغير بين القاسيين القبلي والبعدي ولصالح متوسط القياس البعدي.

r. مناقشة نتائج المجموعة التجريبية في مستوى الأداء المهاري "لمهارات الرقص الحديث

$$
\text { المختارة قيد البحث" }
$$

يتضـح من جدول (Tr) وجود فروق دالة إحصائياً بين متوسطي القياسيين القبلي والبعدي للمجموعة التجريبية في مستوى الأداء للمتغيرات المهارية المختارة "قيد البحث" ، يث كانت قيمة "ت" الجدولية عند مستوى معنويـة (0., •) أقل من قيمة "ت" المحسوبة والتي انحصرت مـا بين (Y.90) في مهارة "الحجل" (1) (1/.1) في " حركات التكور والمد " ، وهذا ما يوضحه ، ونسبت

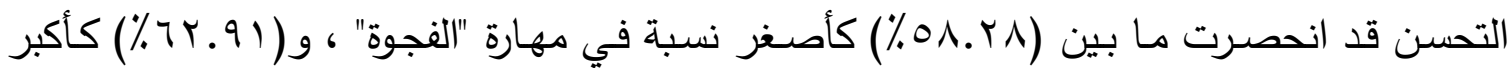
نسبة في مهارة " الغزالة ".

ويتيح استخدام الوسائط التعليمية في مجال تعلم الأنشطة الرياضية المختلفة للمتعلم فرصـة كبيرة للتعلم حيث تساعده على التعبير عن المعارف المختلفة (خبرات - أنشطة - وغيرها) بأكثر من وسيلة في نظام تم التخطيط له جيداً ، وبهذا يتم استخدام أكثر من حاسة من حواس جسمه في استقبال هذه المعارف ، كما تساعد أيضا على تقديم خبرات حية وقوية التأثير ، وتؤدى إلى زيادة بقاء أثر ما يتعلمه مما ينعكس على التعلم من خلال جعله قوياً وحياً ومحسوساً ولذلك تزداد قدرته على استيعاب المراحل المتتابعة لأداء المهارات المختلفة من خلال الرؤية الواضحة والوقت الكافي 
أثناء عرض النماذج المختلفة التي تتضمنها منظومة الوسائط التعليمية ، وهذا يتيح للمتعمين في التربية الرياضية مجالاً أوسع للملاحظة والتفكير والفهم والاكتشاف والابتكار وترسيخ المعلومات في أذهانهم وفى هذا الصدد يؤكد (Chuo , t t أن البحوث وطرق التدريس الحديثة قد أثبتت أن الوسائط التعلمية ضرورية لكل أنواع التعلم واكتساب الخبرات المختلفة حتى تحقق الأهداف التعليمية

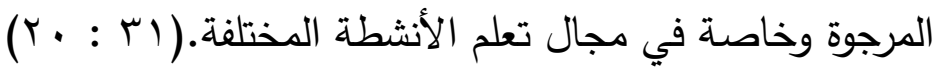

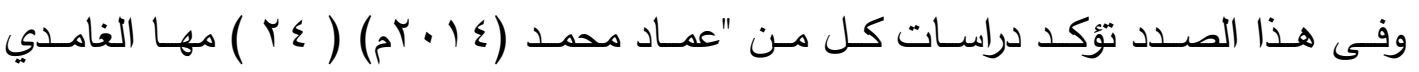

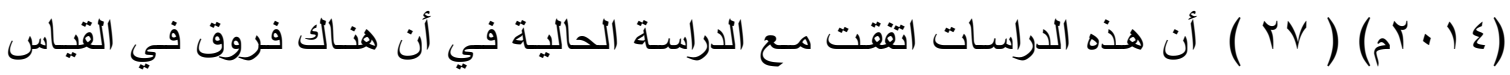
البعدي للمجموعة التجريبية التي تم التدريس لها بالبرنامج باستخدام الرحلات المعرفية عن القياس القبلي ويرجع ذلك إلى توفير مبدأ التنويع والتشويق.

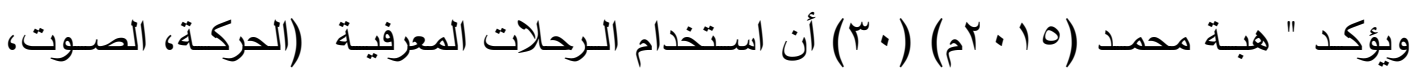
النص، الفيديو، الصـورة) في العملية التعليمية يمكنتا من توصسيل المعلومـة بصسورة أفضل وأسرع للمتعلم وتساعده على تتبيت الخبرات التعليمية لديه وفى نفس الوقت تزيد من فاعلية العملية التعليمية وتجعلها أكثر تشويقاّ، وبالتالي تحقق الأهداف التعليمية المرجوة. وترجع الباحثة هذا الفرق الذى حدث بين القياس القبلي والبعدي في جدول (Tr) إلى البرنامج التعليمي باستخدام الرحلات المعرفية والتي خضست لـه طالبات المجموعة التجريبية والذى يتضمن أكثر مـن وسـيط في عمليـة التعلم مثل (العـرض الطبيعي للمهارة ، العـرض البطيء ، الصـور المسلس ، النص المكتوب ، المؤثرات الصسوتية ، التسجيلات الصسوتية ، الموسيقى ، الفيديو) كل ذلك سـاعد الطالبات على فهم واستيعاب شكل المهارة ومسـار الحركة ووضـوح المراحل المختلفـة والنقاط الفنية لها، وكذلك أعطى الفرصة للمتعلم برؤيسة المهارة بصورة واضحة ولمرات عديدة والتأكيد على جميع مراحلها ، مما يعمل على تثبيتها ويجعل عملية التعلم سهلة وشيقة ، كل ذلك أدى إلى استثارة دافعيـه الطالبـات (المجموعـة التجريبيـة) نحو الاسـتمرار في التعلم لزيـادة فاعليـه أداءهـن المهارى للمهارات المختارة "قيد البحث" وتزيد من قدرتهم على الابتكار الحركي. ץ.عرض نتائج المجموعة التجريبية في مستوى التحصيل المعرفي "لمهارات الرقص الحديث 


\section{جدول (Y )}

دلالة الفروق بين متوسطى القياسيين القبلي والبعدي ونسب التغير للمجمو عة التجريبية في

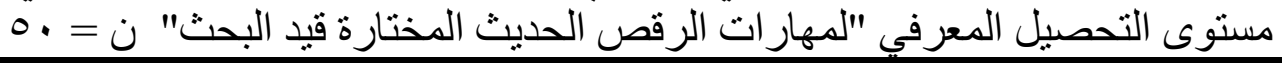

\begin{tabular}{|c|c|c|c|c|c|c|c|}
\hline \multirow[b]{2}{*}{ نسبة التغير } & \multirow{2}{*}{$"$} & \multirow{2}{*}{ الفرق بين } & \multicolumn{2}{|c|}{ القياس البعدي } & \multicolumn{2}{|c|}{ القياس القبلي } & \multirow{2}{*}{ المتغيرات } \\
\hline & & & $\varepsilon^{ \pm}$ & 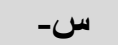 & $\varepsilon^{ \pm}$ & س- & \\
\hline$\% \varepsilon V, 7 \mu$ & $r r, 10$ & $1 V, \cdot 9$ & 1,97 & $\Gamma \bullet, \wedge \wedge$ & $r, V_{0}$ & $11, \vee 9$ & اختبار التحصيل المعرفي \\
\hline
\end{tabular}

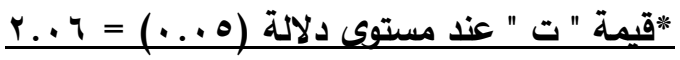

يتضح من جدول (؟ Y) وجود فروق دالة إحصائياً بين متوسطى القياسيين القبلي والبعدي للمجموعة التجريبية فى مستوى التحصيل المعرفي ولصالح القياس البعدي. ع ـمناقشه نتائج المجموعة التجرببية في مستوى التحصيل المعرفي "لمهارات الرقص الحديث

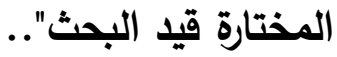

يتضـح من جدول (ع r) وجود فروق دالة إحصـائياً بين متوسطي القياسيين القبلي والبعدي للمجموعة التجريبية في مستوى التحصيل المعرفي لمهارات الرقص الحديث قيد البحث حيث كانت

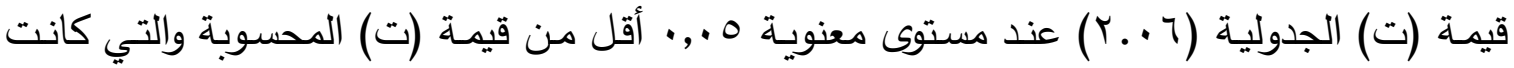

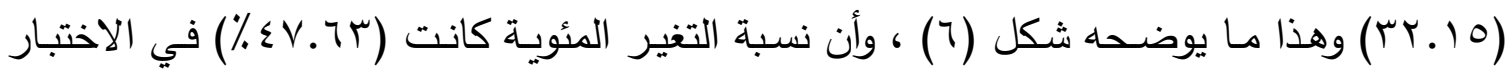
المعرفي لمهارات الرقص الحديث قيد البحث. وترجع الباحثة هذه الفروق إلى أن استخدام الرحلات المعرفية يمكن من خلالها التعبير عن أي معلومة تتعلق بالمهارات الرياضية بوسائل عديدة مثل (الصوت ، النص المكتوب) وبالتالي يتولد لدى المتعلم الفاعلية في تعلم المعارف والمعلومات ، فالمعلومة عندما تقدم للمتعلم بأكثر من وسيلة تخاطب أكثر من حاسة من حواس المتعلم وبالتالي تكون أكثر إيجابية وفاعلية. وقد أكدت نتـائج الكثير مـن البحـوث والدراسـات المختلفـة في مجـال اسـتخدامات الوسـائط التعليمية في مجال تعلم العديد من مهارات الأنشطة الرياضـية المختلفة ، ومنهـا دراسـة كـلا من

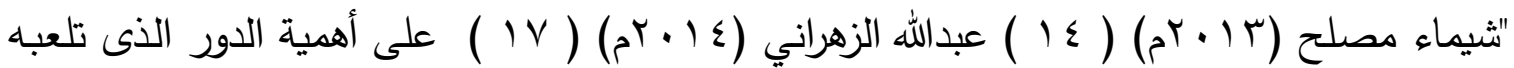
الوسائط التعليمية وعلى مدى فاعليتها في العملية التعليمية بجوانبها المختلفة. 
وبذلك يكون قد تحقق صحة مـا جاء بالفرض الثاني من فروض البحث والذي ينص على التالي: "وجود فروق دالة إحصائياً بين متوسطي القياسيين القبلي والبعدي للمجموعة التجربيية في مستوى الأداء للمتغيرات المهارية المختارة "قيد البحث" ومستوى التحصيل المعرفي ولصسالح متوسط القياس البعدي". ثالثاً: عرض ومناقشة نتائج الفرض الثالث. ا ـ عرض نتائج مجموعتي البحث التجريبية والضابطة في مستوى الأداء المهاري "لمهارات الرقص الحديث المختارة قيد البحث" جدول (ro)

دلالة الفروق بين متوسطي القياسيين البعديين ونسب التغير لمجموعتي البحث التجريبية والضابطة في مستوى الأداء المهاري "لمهارات الرقص

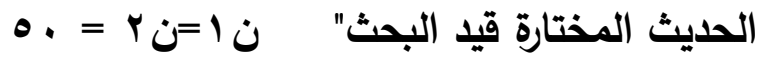

\begin{tabular}{|c|c|c|c|c|c|c|c|c|}
\hline \multirow{2}{*}{ ن التغبر } & \multirow{2}{*}{ " قيمة " } & \multirow{2}{*}{ المترق بين } & \multicolumn{2}{|c|}{ الضابطة المجة } & \multicolumn{2}{|c|}{ التجموعة التجبية } & \multirow{2}{*}{ المتغيرات المهارية } & \multirow[t]{2}{*}{ b } \\
\hline & & & $\varepsilon^{ \pm}$ & س س & $\varepsilon \pm$ & س س & & \\
\hline$\% 10 . \leqslant V$ & $r .1 r$ & $1 . r 0$ & 1.87 & $7 . \wedge r$ & .94 & $\wedge . \cdot \wedge$ & الممشى & .1 \\
\hline$\% \leq \leqslant$ & 0.71 & 1.17 & $\therefore 9$. & 7.11 & . vo & $\Lambda . . \varepsilon$ & الجري &.$r$ \\
\hline$\% 47.19$ & $\begin{array}{c}11 . v \\
\wedge\end{array}$ & r.91 & $1 . .4$ & 0.14 &. .14 & 1.. $\varepsilon$ & الحجل & r \\
\hline$\% \leqslant r . \wedge \wedge$ & $\begin{array}{c}1 Y .7 \\
1\end{array}$ & $r .7 r$ & 1.1. & \&.7r &. .71 & N.ro & الارتداء & $\varepsilon$ \\
\hline \% Y I. & $\Lambda . r \Lambda$ & 1.11 &. .99 & T.YO &.$\wedge 1$ & $V .97$ & النجمة & .0 \\
\hline$\% \leqslant V . \Delta r$ & $\begin{array}{c}11.1 \\
1\end{array}$ & r.qr & .87 & &. .71 & N.Yo & الغزالة & .7 \\
\hline 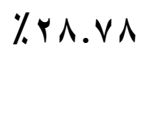 & $1 \cdot .1$ & T.TE & $\cdot . \wedge \wedge$ & $0 . v 9$ &. .71 & $\Lambda .1 \mu$ & الموزة &.$v$ \\
\hline$\% 1.01$ & A.VI & Y. \& Y & .94 & $0 . r \mu$ &.$\vee \wedge$ & V.Vq & الفجوة &.$\wedge$ \\
\hline \% rA. r & $\begin{array}{c}1 \cdot .5 \\
9\end{array}$ & T.rT & $\because \vee \wedge$ & $0.9 r$ & . . & N.Yo & وثبة الحصان & .9 \\
\hline$\% r r . . v$ & Ir.V & Y.OS & $1 . .1$ & $0 . \mu \wedge$ &.$v r$ & V.9r & الزحلقة & 1. \\
\hline
\end{tabular}




\begin{tabular}{|c|c|c|c|c|c|c|c|c|}
\hline & $\varepsilon$ & & & & & & & \\
\hline \%rr.Ar & ir.. & Y.VO & $\cdot . \wedge \wedge$ & 0.74 & $\therefore \leqslant 9$ & $\Lambda . r \Lambda$ & حركات التكور والمد & .11 \\
\hline$\%$ \& \&.V० & $\begin{array}{c}10.9 \\
7\end{array}$ & $r .01$ & $\cdot . \wedge r$ & $\varepsilon . \leqslant Y$ & 7.74 & ^... & حركات التوزان من & $.1 r$ \\
\hline$\% \leq \varepsilon . \vee$. & $\begin{array}{c}\text { rr.o } \\
q\end{array}$ & r.t. V & 7. & $\{.0\}$ &. .01 & N.YI & حركات التوزان من & .11 \\
\hline
\end{tabular}

يتضح من جدول (ro) وجود فروق دالة إحصائياً بين متوسطي القياسيين البعديين لمجموعتي البحث التجريبية والضـابطة في مستوى الأداء للمتغيرات المهاريـة المختارة "قيــ البحث" ولصـالح

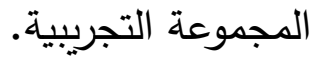
مناقثـة نتائج مجهوعتي البحث التجريبية والضـابطة في مستوى الأداء المهاري "لمهارات الرقص الحديث المختارة قيد البحث" يتضح من جدول (؟ Y) وجود فروق دالة إحصائياً بين متوسطي القياسيين البعديين لمجموعتي البحث التجريبية والضـابطة في مستوى الأداء للمتغيرات المهاريـة الدختارة "قيد البحث" حيث كانت قيمة "ت" الجدولية عند مستوى معنوية (0.,.) أقل من قيمة "ت"

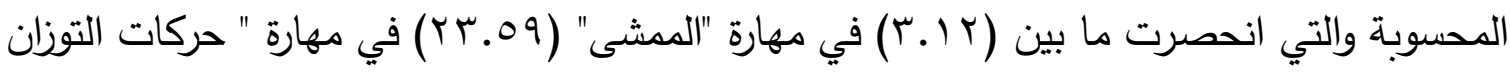

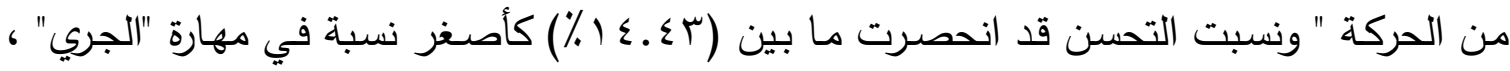

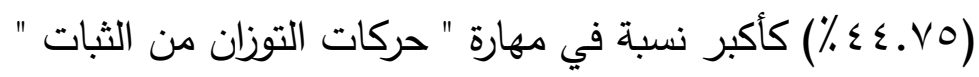
وترجع الباحثة هذه التتجية إلى أن أسلوب الرحلات المعرفية يعد من التقنيات الحديثة ، وأحد إبداعات وتطبيقات تكنولوجيا التعليم في تدريس وتعلم المهارات الحركية في أنشطة التربية الرياضية بأسلوب مشوق وجـاذب لانتباه حواس المتعلمـة ، حيث انتقل التركيز مـن طريقة الثـرح اللفظي والنموذج والأوامر في التعليم إلى التركيز على عمليات الاتصال بمشاهدة المهارة عن طريق الفيديو والصور المسلس والعرض البط ، وكذلك مـع وجود النص المكتوب والمقروء والمؤثرات الصسوتية والموسيقى داخل البرنامج التعليمي، كل ذلك يعطى فرصـة كبيرة للمتعلمة لمشاهدة النواحي الفنية للمهارة بصورة واضحة ويعطى للطالبة التصور الحركي الصحيح للمهارة كل ذلك أدى إلى تفاعل 
الطالبات مـع البرنامج بإيجابية وبشكل يثير دوافعهم للتعلم دون الثعور بعدم الرغبة في الحصول على المعلومـات ، حيـث تكمن أهميـة اسـتخدام الوسـائل التكنولوجيـة في عمليـة التعلم في التربيـة الرياضية في استثارة اهتمام المتعلم وإثباع حاجاته للتعلم وإثراء مجالات الخبرة لديه،، كما أنها تسهم في تتمية قدرته على التأمل ودقة الملاحظة ، حيث تقدم لهن المعلومة من خلال برامج متكاملة بأزه الألوان والخلفيات والحركات والمؤثرات الصـوتية ، لكى تعطى الفرصـة للمتعلمـة لمشـاهدة المهارات الحركية بمراحلها الفنية بأحسن صورة حتى تتمكن ان تتعلمها وتؤديها بشكل صحيح.

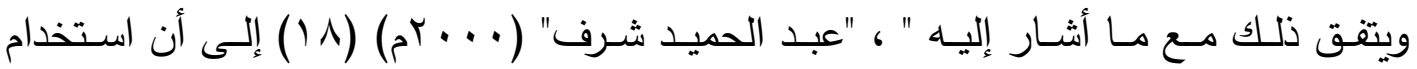
تكنولوجيا التعليم تساعد في عملية التعلم الحركي من خلال التغذية الراجعة التي تؤثر تأثيراً إيجابياً في بنـاء وتطوير التصـور الحركي عند المـعلم ، وتوضـح مواضـع الخطـأ وتصـحه وتعدلـه نحو الأفضـل ممـا يؤدى في النهايـة إلى الوصـول بـالمتعلم إلىى أقصسى درجـة إجـادة في تعلم مهارات الأنشطة الرياضية.

كما ترى الباحثة أنه لابد من تعديل وتطوير البرامج التعليمية المقدمة للمتعلمين وصياغتها بطرق تعمل على تنشيط القدرات والطاقـات اللازمـة لعمليـة التعلم والتحصيل مـن خـلال إستخدام الأساليب التدريسية المناسبة لهم، فإننا بذلك نساهم في وضع اللبنة الأولى لبداية حقيقية للتعلم الفعال الذى يجعل المتعلم ونشاطه الذاتي وطاقاته وقدراته محوراً للعملية التعليمية ومشاركاً في تنفيذها ، وذلك قد يساعده على توجيه نشاطه الزائد إلى ما هو مفيد وهادف. وتؤكد " هبـة محمد (0 1 • rم) ( • (r) على أن الوسـائط تؤدى إلى تغييراً شـاملاً في العلميـة التعليمية وينعكس ذلك على المتعلم من خلال ما يمكن أن يوفره لـه هذا الأسلوب الجديد ، كما أن المعلم في هذا الأسلوب يتحول إلى موجه ويصبح المتعلم هو أساس العلمية التعليمية.

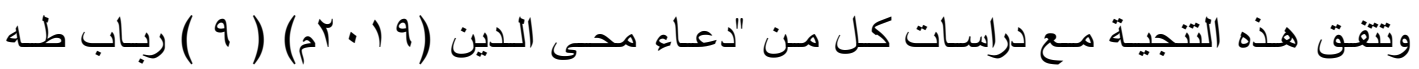

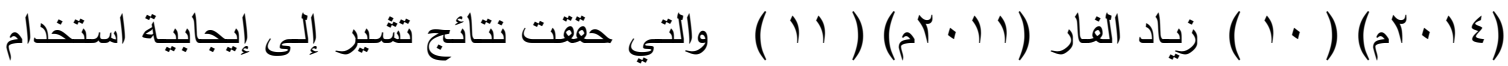
الرحلات المعرفية في التعلم للعديد من الأنشطة الرياضية. ץ.عرض نتائج مجموعتي البحث التجربيية والضابطة في مستوى التحصيل المعرفي لمهارات الرقص الحديث المختارة قيد البحث". 


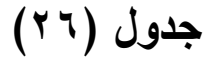

دلالة الفروق بين متوسطي القياسيين البعديين ونسب التغير لمجموعتي البحث التجريبية

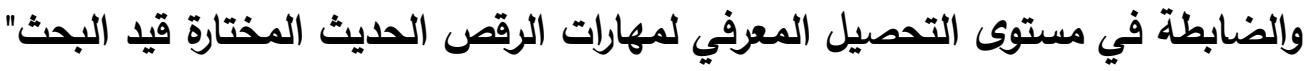

$0 .=r \dot{0}=10$

\begin{tabular}{|c|c|c|c|c|c|c|c|}
\hline \multirow{2}{*}{ التغبية } & \multirow{2}{*}{ " قيمة " } & \multirow{2}{*}{ المتوسطين } & \multicolumn{2}{|c|}{ الضابطوة } & \multicolumn{2}{|c|}{ التجميبية } & \multirow{2}{*}{ المتغيرات } \\
\hline & & & $\varepsilon^{ \pm}$ & س- & $\varepsilon^{ \pm}$ & س- & \\
\hline \% & v. q. & 0.74 & r.T & r..ro & 1.97 & ro. 11 & اختبار التحصيل \\
\hline
\end{tabular}

يتضح من جدول (Tr) وجود فروق دالة إحصائياً بين متوسطي القياسيين البعديين لمجموعتي البحث التجريبية والضابطة في مستوى التحصيل المعرفي ولصالح متوسط القياس البعدي للمجموعة التجريبية.

؛.مناقثه نتائج مجموعتي البحث التجريبية والضابطة في مستوى التحصيل المعرفي لمهارات

\section{الرقص العديث المختارة قيد البحث".}

يتضح من جدول (Tr) وجود فروق دالة إحصائياً بين متوسطي القياسيين البعديين لمجموعتي لهوني البحث التجريبية والضابطة في مستوى التحصيل المعرفي لمهارات الرقص الحديث قيد البحث حيث

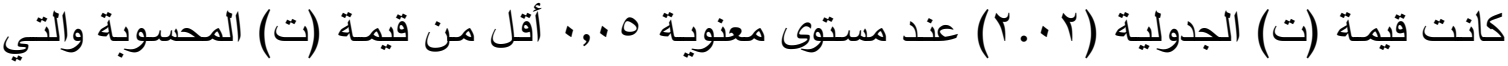
كانت (•.9.9) وهذا ما يوضحه شكل (^) وأن نسبة التغير المئويـة كانت (.9.9\%) في الاختبار المعرفي لمهارات الرقص الحديث قيد البحث. وترجع الباحثة هذه الفروق بين المجموعتين إلى أن طريقه التعلم باستخدام الرحلات المعرفية التي خضعت لها طالبات المجموعة التجريبية تنظر إليهن على أنهن متفاعلات وغايتها نموهن ونضجهن وحصولهن على المعلومة دون ملل فيكون دورهن إيجابي نشط في العملية التعليمية مما يزيد من دافعيتهن للتعلم ، كما أن طريقه التعلم باستخدام الرحلات المعرفية يعامل الطالبة على أنها 
ليست مجرد مستقبلة للمعلومـات وإنمـا هي مشـاركة وجامعـة لهذه المعلومـات والمعـارف التي تتسم بتنوعها وبتعدد مصادرها في حين أن الطريقة التقليدية باستخدام الثرح اللفظي وأداء النموذج العملي التي خضـعت لها طالبات المجموعة الضـابطة تتظر إليهن على أنهن مجرد مستقبلات ومتلقيات للمعلومات فقط، فيكون دورهن سلبي في العملية التعليمية مما يقلل من دافعيتهن للتعلم والأمر لا يقتصـر على مجـرد وجـود فروق فقط ، بـل حققت المجموعـة التجريبيـة نسـبه تحسـن أعلى مـن المجموعة الضابطة في مستوى التحصيل المعرفي. ويؤكد " عبدالعزيز طلبة ( • • rم) (T ( ) بأن النظرة القديمة في التعلم (الطريقة التقليدية) ترى المتعلم مجرد عقل تصب فيه المعلومات فقط وهو مجرد متلقي ، أما النظرة الحديثة في التعلم فتنظر للمتعلم على أنه كائن حي متفاعل وغايتها نموه ونضجه وليس الهدف هو حفظ المعلومات. وتتفق هذه التتجية مع دراسات كل من السيد يس حسن مرزوق ( • •rم ) ( ( )عدى طارق

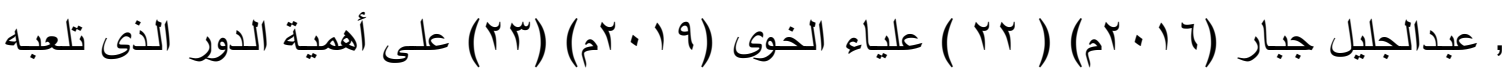
الوسائط التعليمية وعلى مدى فاعليتها في العملية التعليمية بجوانبها المختلفة. وبذلك يكون قد تحقق صحة مـا جاء بالفرض الثالث من فروض البحث والذي ينص على التالي: "وجود فروق دالـة إحصـائياً بين متوسطي القياسيين البعديين لمجموعتي البحث التجربيية والضـابطة في مستوى الأداء للمتغيرات المهاريـة المختارة "قيد البحث" ومستوى التحصيل المعرفي ولصالح المجموعة التجريبية".

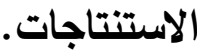
في حدود أهداف البحث والنتائج التي تم التوصل إليها يمكن استتاج ما يلى: ا- البرنامج التعليمي التقليدي الذى استخدام مع "المجموعة الضـابطة" أدى إلى تحسين في جوانب التعلم لمهارات الرقص الحديث المختارة "قيد البحث" ، حيث أظهرت فروق معنويـة بين القياس القبلي والبعدي لصالح القياس البعدي وكذلك في نسبة التحسن لصالح القياس البعدي. 
ץ- الرحلات المعرفية التي طبقت على "المجموعـة التجريبية" أدت إلى تحسين في جوانب التعلم لمهارات الرقص الحديث المختارة "قيد البحث" ، حيث أظهرت فروق معنويـة بين القياس القبلي والبعدي لصالح القياس البعدي وكذلك في نسبة التحسن لصالح القياس البعدي. ب- الرحلات المعرفية كانت أكثر تأثيراً على مستوى التحصيل المعرفي من الأسلوب التقليدي. التوصيات ا - الاهتمام باستخدام الوسائط المتعددة عن طريق استخدام الحاسب الآلي كوسائل تساير طبيعة

$$
\text { العصر الحالي. }
$$

r- الاهتمام بوضـع برامج تعليمية باستخدام الرحلات المعرفية لتحسين وتتمية مهارات الرقص الحديث حتى يمكن الإرتقاء بمستوى تعلم مهارات الرقص الحديث لطالبات كليات التربية

$$
\text { الرياضية. }
$$

ب- الاهتمـام بإنتاج بـرامج تعليميـة عـن طريـق اسـتخدام الـرحلات المعرفيـة في كـل الألعـاب

$$
\text { الرياضية. }
$$

ع- الاستعانة بكل ما هو جديد ومبتكر في مجال تكنولوجيا التعليم لتعلم الأداء الحركي للأنشطة

الرياضية المختلفة.

\section{قائمة المراجع}

$$
\text { ا ـ أحمد عبدالله (r ا • rم): التعليم عن بعد دار الكتاب الحديث , القاهرة }
$$

Y. أسـامة محمد عبد العزيز (r · . rم):"تأثير برنـامج تعليمي باستخدام الوسـائط المتعددة والمنفردة على تعلم بعض مهارات المصارعة لطلبة كلية التربية الرياضية"، رسالة ماجستير غير منشورة، كلية التربية الرياضية، جامعة المنيا. r. السيد يس حسن مرزوق ( • ( • rم):"بناء برمجية تعليمية معدة بتقنية الوسائط المتعددة كعائد معلوماتي (مسبقة-مرجأة) وتأثيرها في تعلم بعض المهارات الأساسية لكرة السلة لطلبة"، رسالة ماجستير غير منشورة ، كلية التربية الرياضية، جامعة طنطا. 
ع. آّيـة الأحمدي (•r • r م): تأثير برنـامج تعليمي باستخدام الرحلات المعرفية على تعلم بعض مهارات ألعاب القوى لتلاميذ الحلقة الثانية من التعليم الأساسي , رسالة دكتوراه غير منشورة , كلية التربية الرياضية , جامعة بنها . ه. الغريب زاهر (9 . . rم): التعليم الإلكتروني من التطبيق إلى الإحتراق , عالم الكتب , القاهرة. 7. إجـلال محمد إبراهيم ، ناديـة محمد درويش (ب . . rم): الرقص الابتكاري الحديث، دار الهنا،

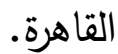
V. إجـلال محمد إبراهيم ، ناديـة محمد درويش(T + . rم): الرقص الابتكاري الحديث، دار الكتب للنشر ، القاهرة. ^. خالد إبراهيم (1 ( • rم): استراتيجية الرحلات المعرفية وتأثيرها في نواتج التعلم ببعض مهارات الكرة الطائرة لتلاميذ المرحلة الإعدادية ، رسالة ماجستير غير منشورة ، كلية التربية الرياضية للبنات ،جامعة الإسكندرية 9 ـ دعاء محى الدين (9 ( • rم): فاعلية استراتيجية الرحلات المعرفية عبر الويب في تعلم مسابقة الوثب الثلاثي لدى طالبات كلية التربية الرياضية , المجلة العلمية للتربية البدنية وعلوم الرياضـة , المجد (^) ر , الجزء (1) , كلية التربية الرياضية , جامعة حلوان • • ا . رباب طه (ع ( • rم): فاعلية إستخدام الرحلات المعرفية في تحسين الجانب المعرفي وبعض المهارات الحركيـة بـدرس التربيـة الرياضـية لتلميذات المرحلـة الإعداديـة , رسـالة ماجستير غير منشورة , كلية التربية الرياضية للبنين , جامعة الإسكندرية .

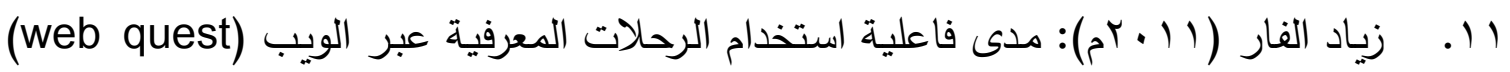
في تدريس الجغرافيا على مستوى التفكير التأملي والتحصيل لدى تلاميذ الصف الثامن الأساسي , رسالة ماجستير غير منشورة , جامعة الأزهر بغزة , فلسطين r ا. . سامح صـابر جابر على( ( . rم): الأسـاليب الفنيـة للرقص الحديث محاولة وضـع منهج اكاديمي للطلاب بالمرحلة النهائية بمدرسة البالية المصرية (دراسـة تطبيقية)، أكاديمية الفنون، المعهد العالي للباليه، قسم طرق تدريس الباليه، القاهرة. 


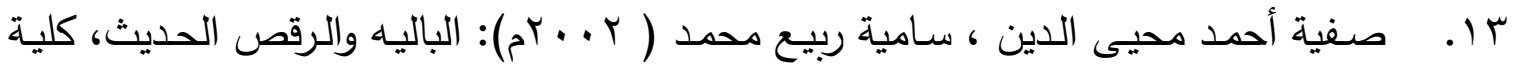
التربية الرياضية للبنات، جامعة حلوان، القاهرة.

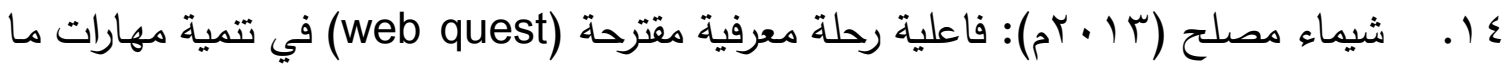
وراء المعرفـة في مـادة الفيزيـاء لطالبـات كليـة العلوم الطبيـة , بحث منشـور , المؤتمر العلمي الثالث للتعلم الإلكتروني والتعليم عند بعد , الرياض •

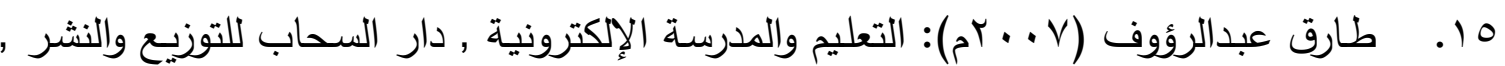

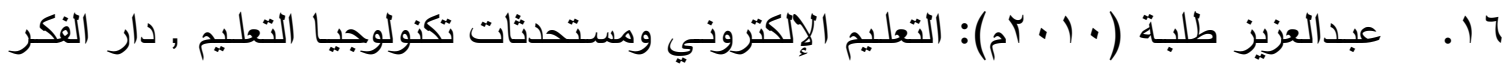

$$
\text { العربي , القاهرة . }
$$

V V . عبدالله الزهرانى (؟ ا • rم): فاعلية الرحلات المعرفيـة الافتراضية في تتمية مهارات التعلم التعاوني لدى عينة من طلاب المرحلة المتوسطة في منطقة الباحة , رسالة ماجستير منشورة , كلية التربية , جامعة الباحة .

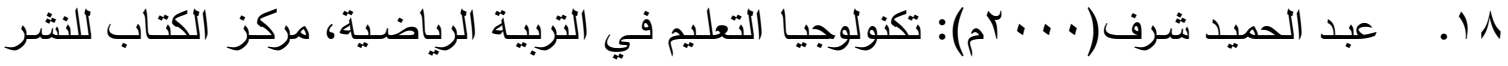

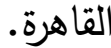

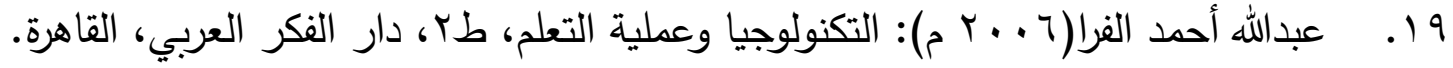

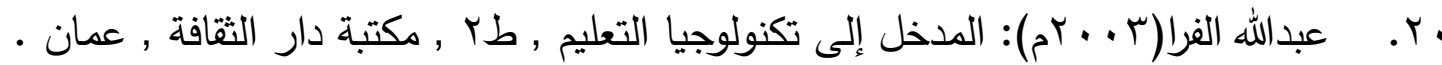
ا Y. عبير حسن , سـامح سليم (•r.r.r): تأثير استخدام الرحلات المعرفية عبر الويـب على التحصيل المعرفي لطلاب كلية التربية الرياضية ببورسعيد , المجلة العلمية للبحوث والدراسات في التربية الرياضية , المجلد (•ع) , الجزء (ץ) , كلية التربية الرياضية , جامعة بورسعيد.

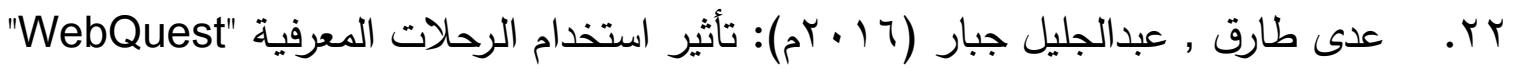
كبديل للدورات التدربيية لمدربي الجودو , المجلة العلمية للتربية البدنية وعلوم الرياضـة , العدد • كلية التربية الرباضية للبنين , جامعة حلوان (VV) 


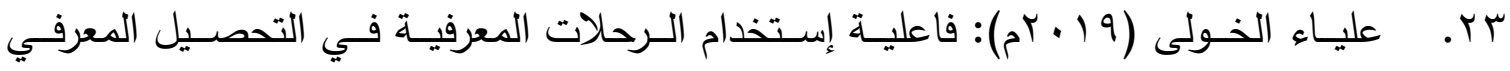
والمهارات التدريسية لطالبات بكلية التربية الرياضية بطنطا , رسالة دكتوراة غير منشورة , كلية التربية الرياضية , جامعة طنطا .

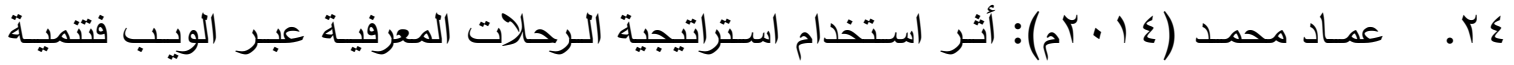
التحصيل المعرفي وبقاء أثر التعلم والاتجاه نحوها لدى عينة من طلاب جامعة أم القرى , مجلة التربية , العدد (• ا () , الجزء (ץ) , كلية التربية , جامعة الأزهر •

هץ. ليلى السيد فرحات (1 . . rم): القياس المعرفي الرياضي، مركز الكتاب للنشر، القاهرة

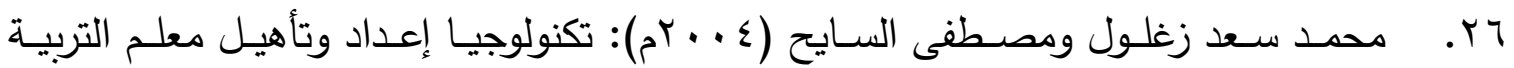
الرياضية، طب، دار الوفاء لدنيا الطباعة والنشر ، الإسكندرية.

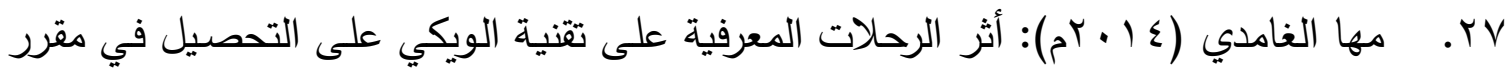
تطبيقات التعلم الإلكتروني لاى كالبات كلية التربية , رسالة ماجستير غير منشورة , كلية التربية , جامعة الباحة , المملكة العربية السعودية ,

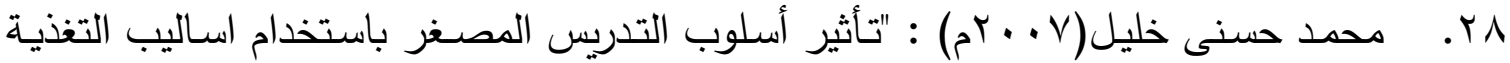
الراجعة على تعلم بعض مهارات كرة السلة لدى تلاميذ المرحلة الإعدادية"، رسالة ماجستير غير منشورة، كلية التربية الرياضية، جامعة المنصورة. q. . نبيل عزمي (ع ( • rم): بيئات التعلم التفاعلية , دار الفكر العربي , القاهرة • r. هبة محمد (0 1 • ب م): أثر توظيف الرحلات المعرفية عبر الويب "Quest web" في مقرر طرق تدريس التربية الرياضية لتمية الجانب المعرفي لاى طالبات شعبة التدريس , مجلة أسيوط لعلـوم و فنون التربيـة الرياضـية , العـد ( • ع) , الجـزع (ب) , كليـة التربيـة الرياضـية , جامعـة

\section{ثانيًا: المراجع الأجنبية:}

31. Chuo , $t$ (2004): the Effect of the web quest writing instruction on efl learners writing performance, writing apprehension and perception , unpublished doctoral dissertation, la sierra university, china . 
32. Dodge, B(2001): The building blocks of a Web Quests. Website:Retrieved in:25/5/2010 from:http://Project edtech .sandi . net/staffdev/building blocks /pindex htm,pp51

33. Gaskill, M. ,McNulty, A., Brooks , D.,(2006): learning from webQuests , journal of science education and technology , 15(2

34. Halat ,E A(2008) : The Effects of Designing Web Quests on The Motivation of Pre- Service Elementary School Teachers International of Mathematical Education in Science and Technology , V 39,N6

35. Ikpeze , H \& Boyd , F (2007): web-based inquiry learning facilitating thoughtful literacy with webquests, the reading teacher journal , 60(7)

36. Johnson, lisa E (2005): using technology to enhance in tranation al studies, of social education , v1,n2.

Lara. S\& Reparaz. Ch. (2005): Effectiveness of cooperative learning fostered by working with Web Quest. Electronic Journal of Research in Educational Psychology.Monthly.-vol.21. 